مجلة علوم الإنسان والمجتمع........................................................... محمد عبد الكريم الحوراني

\title{
المجتمع المدني ضرورة وظيفية للدولة
}

الدكتور : محمد عبد الكريم الحوراني

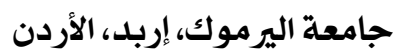

الملخص:

لقد أظهرت الدراسة أن الجمتمع المدني يعمل على بنـاء المسؤولية الجمعية، والتشـاركية

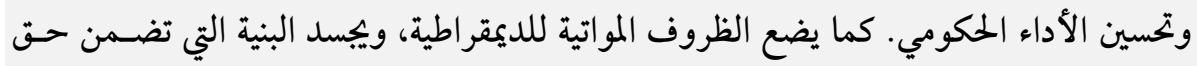

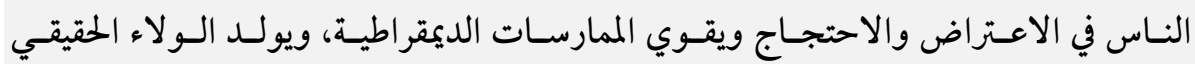

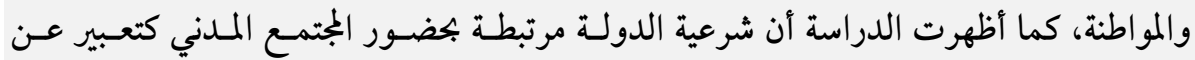

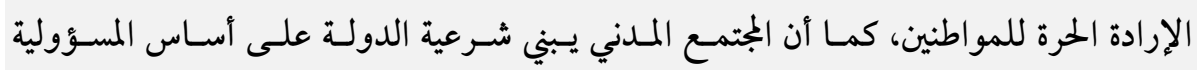

الأخلاقية، وينب الدولة مأزق أزمة الشرعية.

\section{Abstract :}

The study showed that civil society structuring the collective responsibility, participatory, and improving the governmental performance, Besides, civil society puts an appropriate conditions for democracy, and embodies the structure that ensures the peoples right to object and protest, strengthening democratic practices and generates the genuine loyalty and citizenship. In addition, the study showed that legitimacy of state is connected to the presence of civil society which expresses the free will of citizens, Also, civil society Structuring the legitimacy of state in the base of moral responsibility, and avoiding state the dilemma of legitimacy crisis. 
يشير المجتمع المدني إلى "بجموعة من التنظيمات الطوعية الحرة التي تملاً المجال

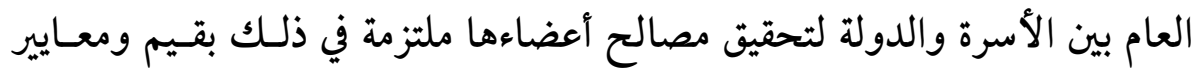

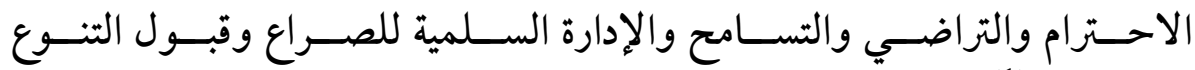

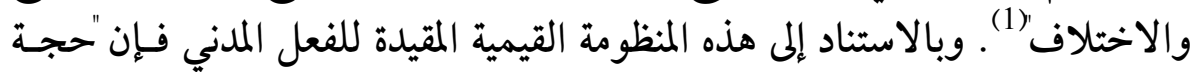

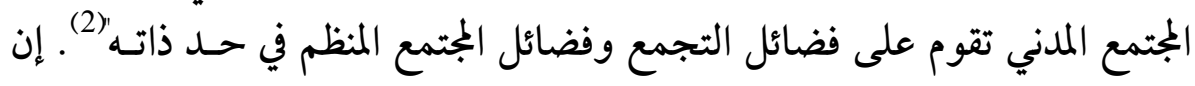

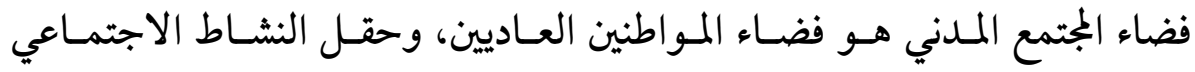

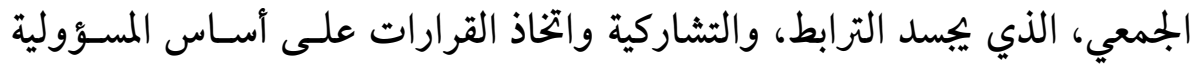

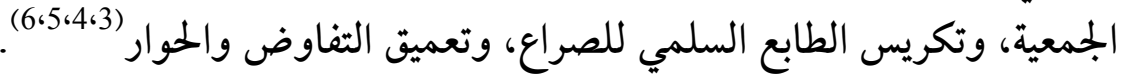

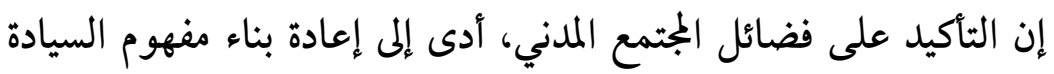
Sovereignty

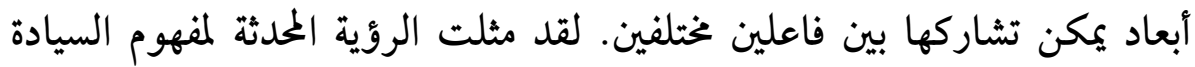

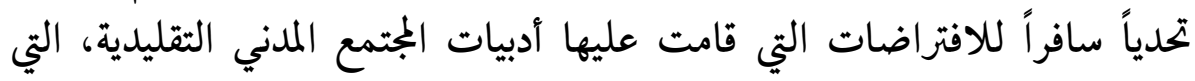

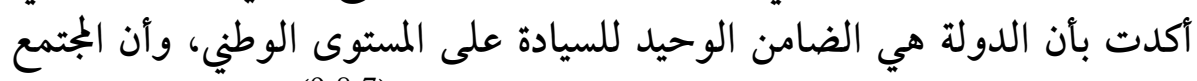

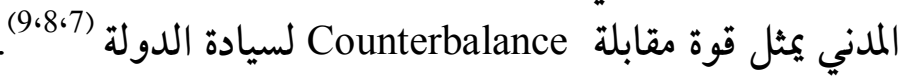

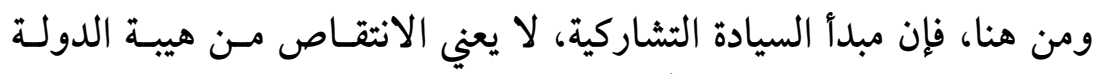

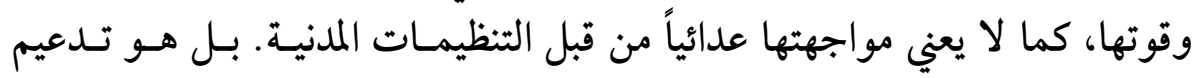

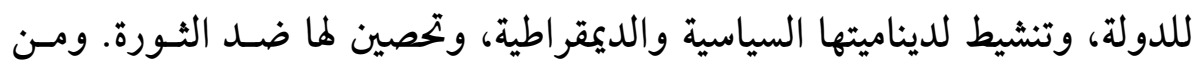

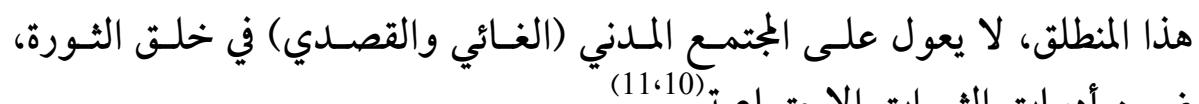
ضمن أدبيات الثورات الاجتماعية (11010).

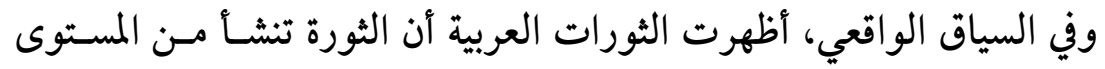

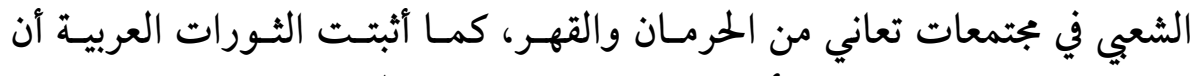

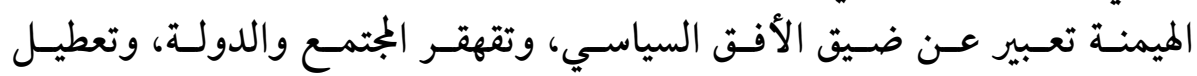

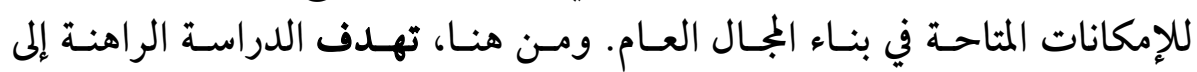




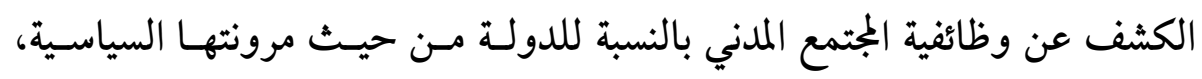

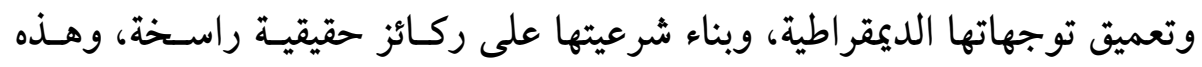

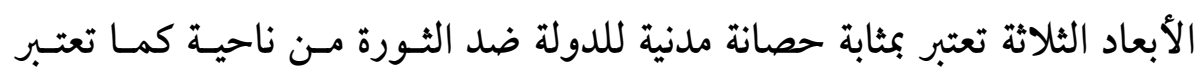

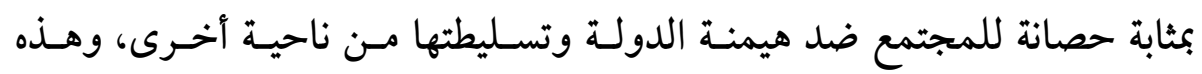

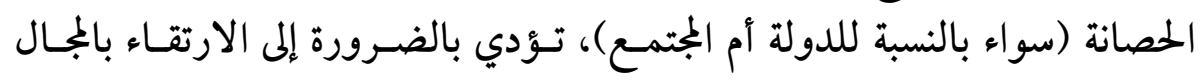

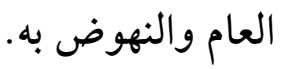

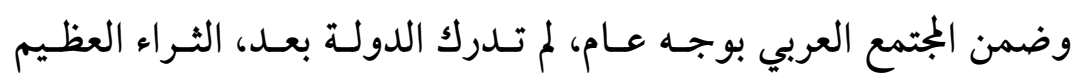

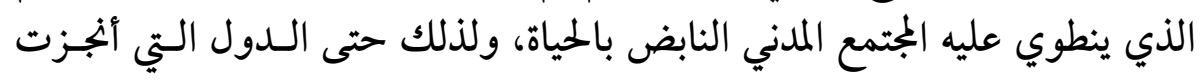

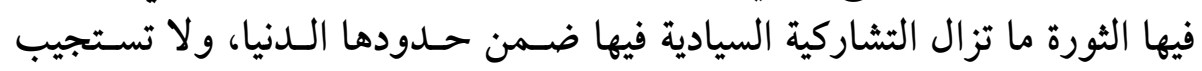

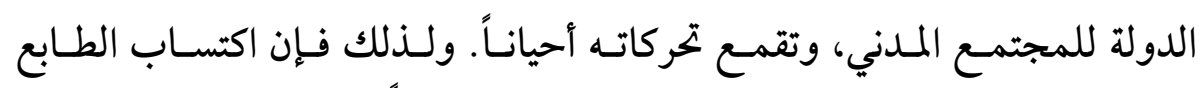

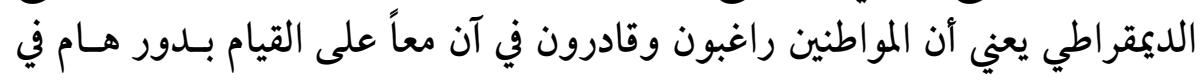

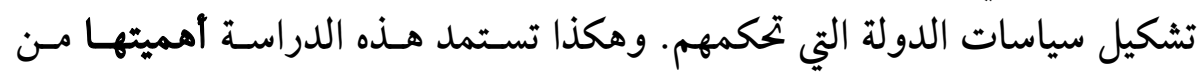

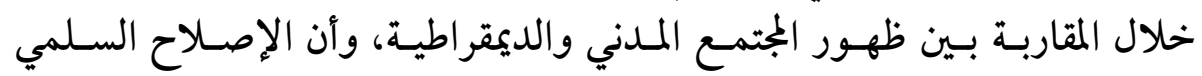

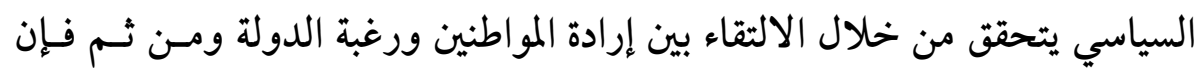

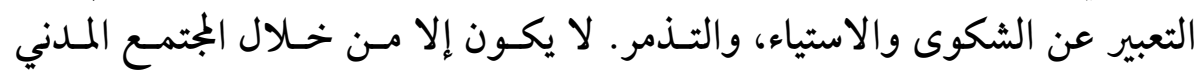

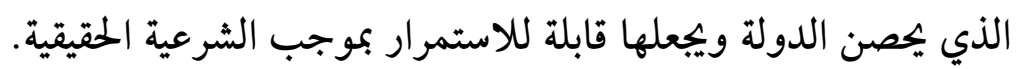

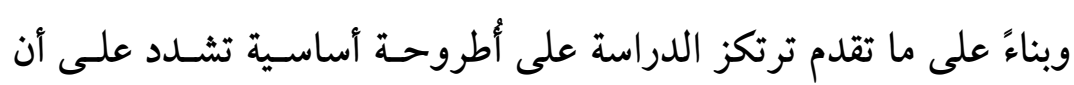

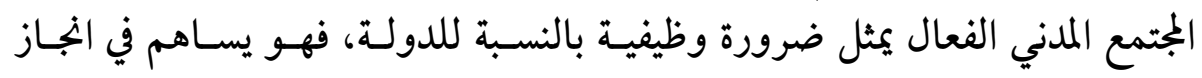

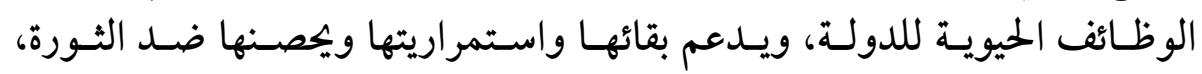

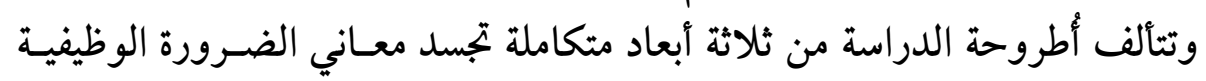

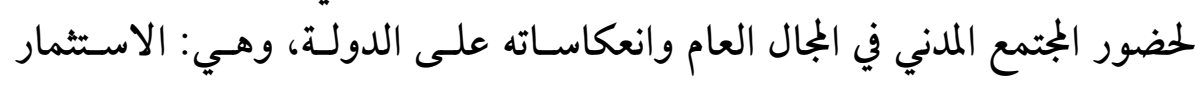
السياسي وتنشيط النزعة السياسية، وتعميق الديمقراطية، وبناء الشرعية. 
الاستثمار السياسي وتنشيط النزعة السياسية

الاستثمار الذي يمكن أن تنجزه الدولة في علاقتها مع الجمتمع، هو السياسـية

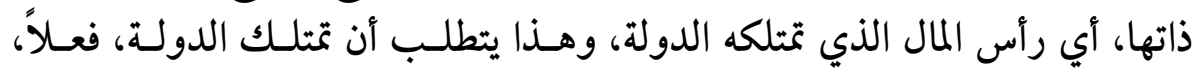
رأس المال السياسي، أي أن تكون الدولة "سياسية.

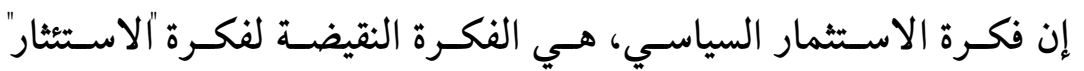

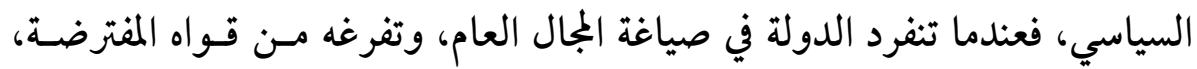

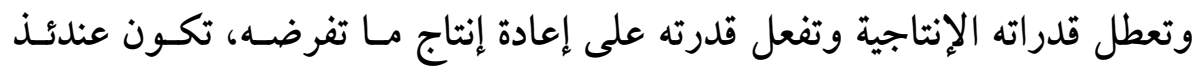

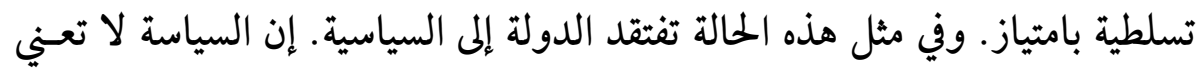

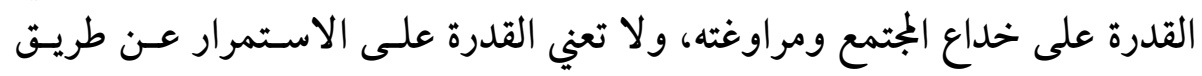

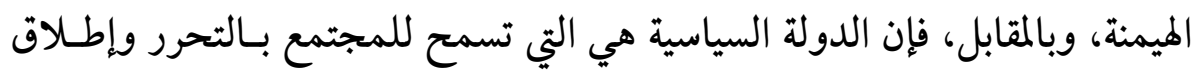

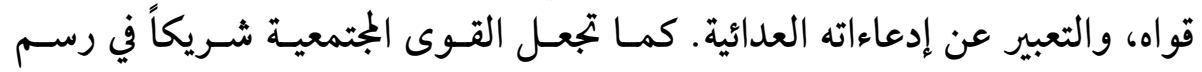
الخارطة الكلية للمجتمع واتجاهاته الآنية والمستقبلية.

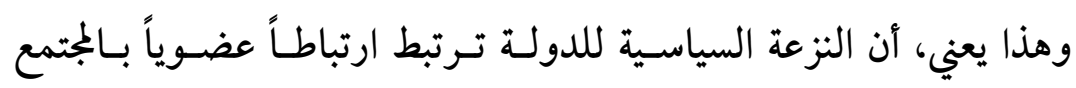
المدني الذي يجسد التعبير الحقيقي عن قـوى المجتمـع، وعقلانيـة ضـميره الجمبعي.

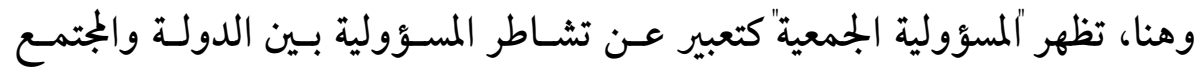

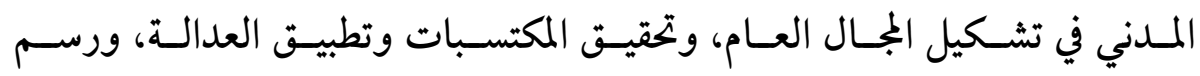

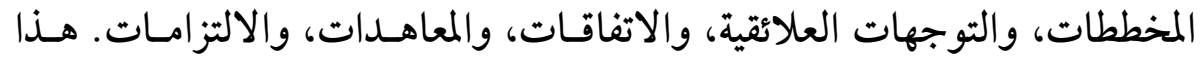

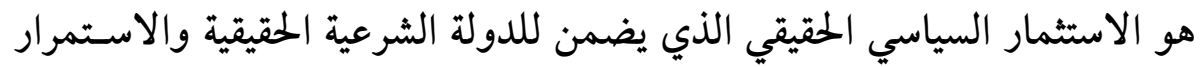

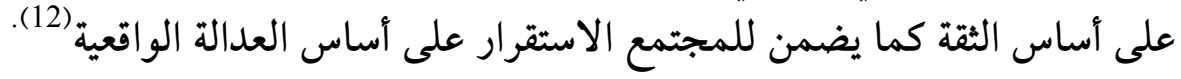
إن هدر السياسة، وتعطيل مبدأ المسؤولية الجمعية، يفضي إلى تفــرد الدولـة المهاء

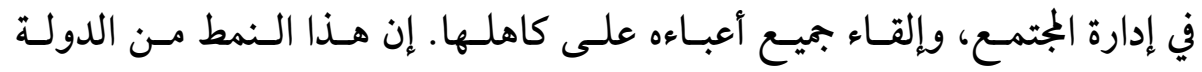

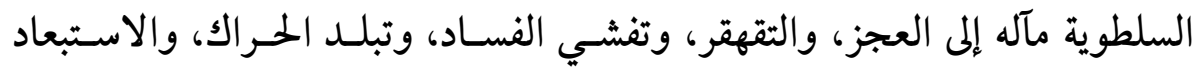

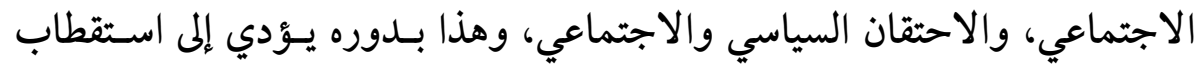




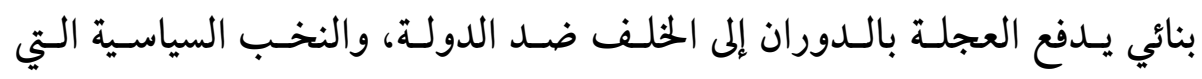

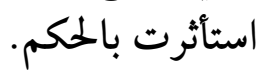

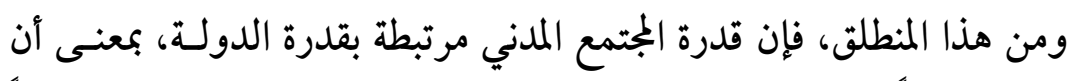

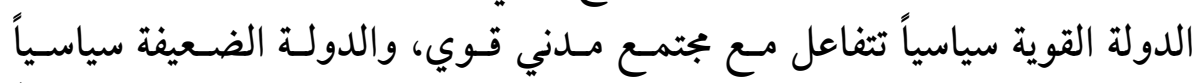

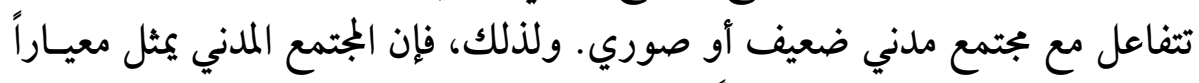

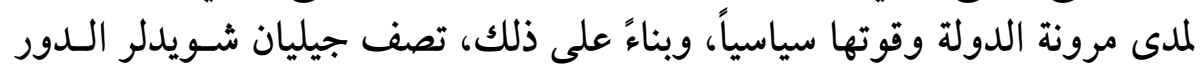

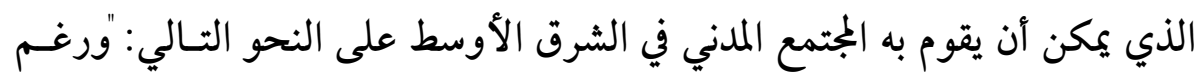

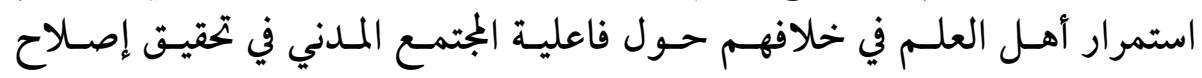

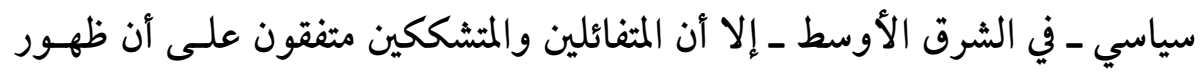

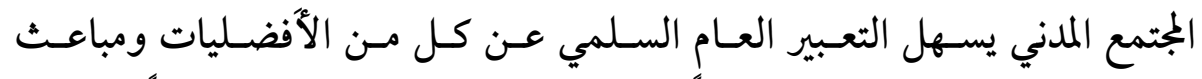

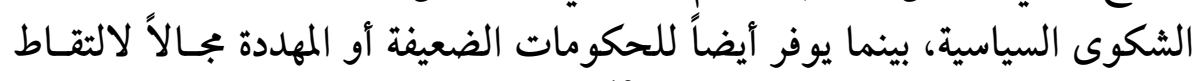

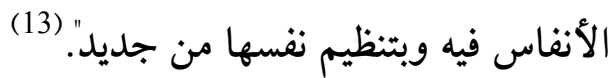

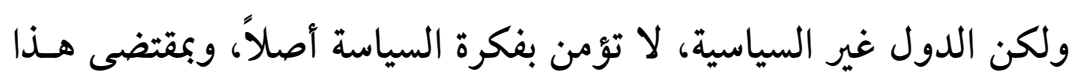

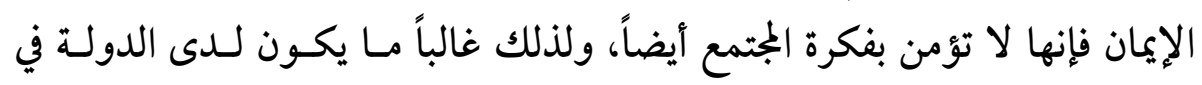

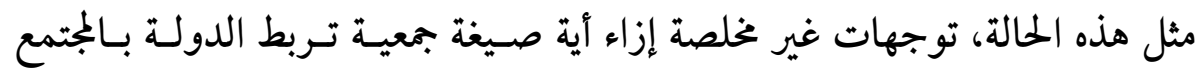

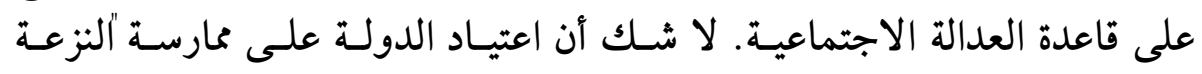

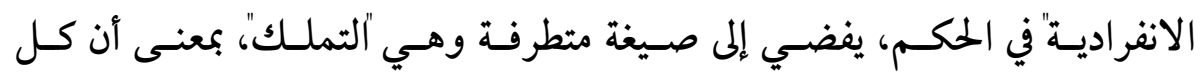

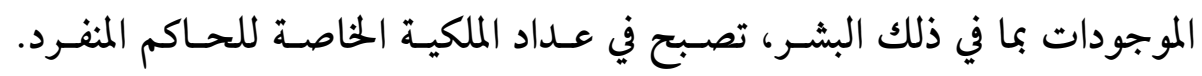

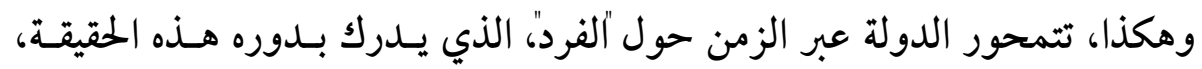

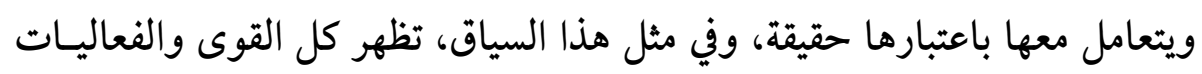
خالية من محتواها الحقيقي، ومفرغة من معناهي مناها البنائي الفعال.

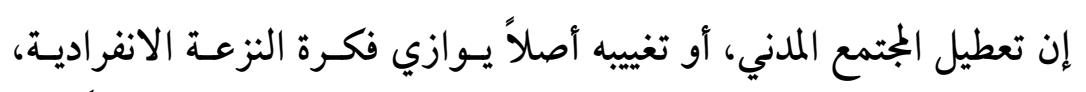

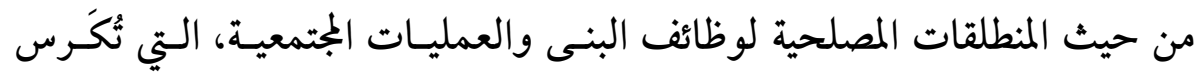

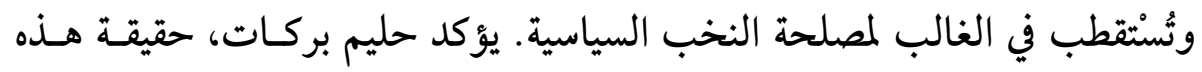

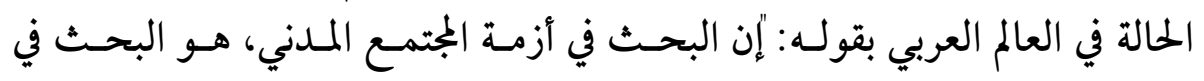


ممارسات الدولة التعسفية للسلطة، لقد سـلبت الدولـة في مختلـف البلـدان العربيـة

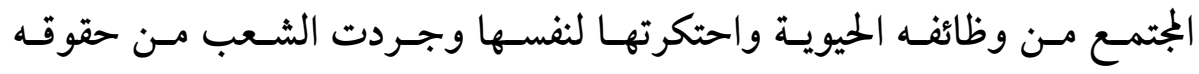

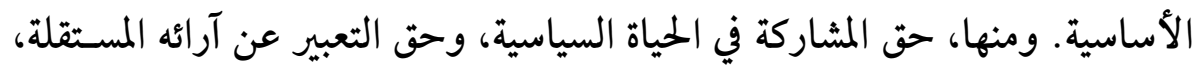

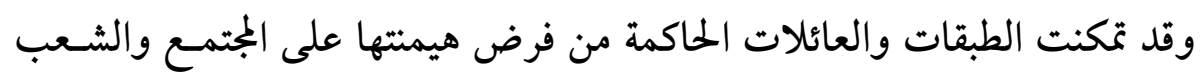

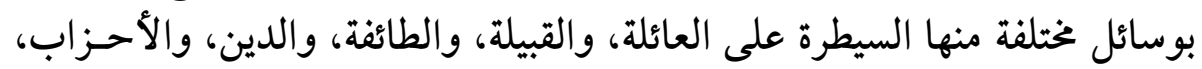

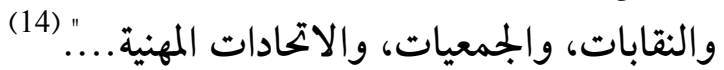

إن الدولة العربية، التي ملأت المجال العام وطغت فيـه، لم تـألف عـبر فـترة

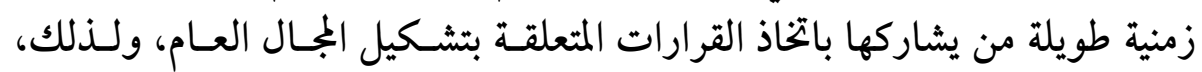

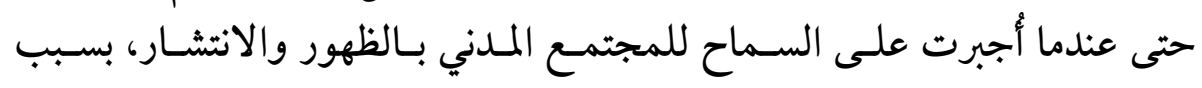

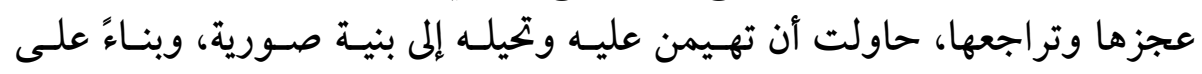

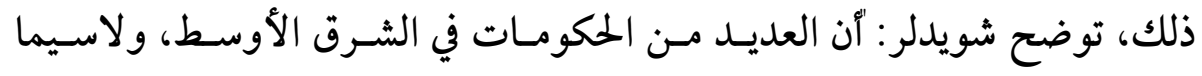

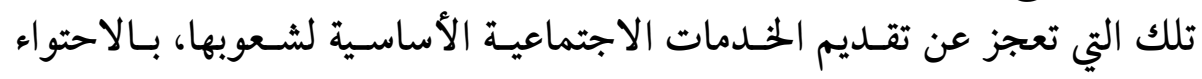

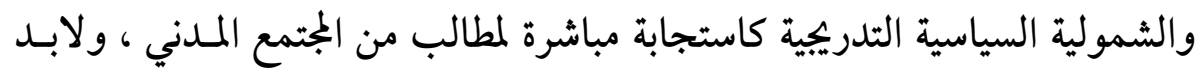

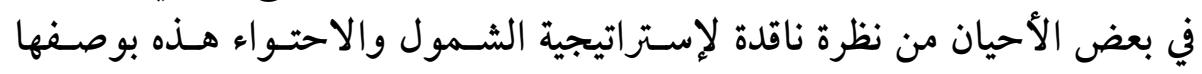

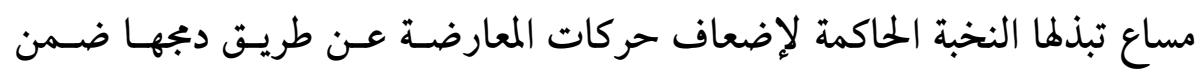

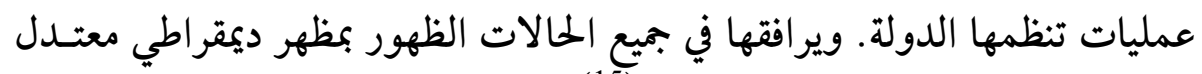

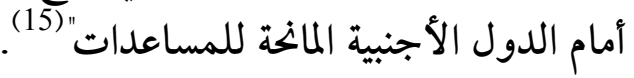

وهذا يعـني، أن النسـق السياسـي المهـيمن يتعامـل مـع الـروابط المجتمعيـة

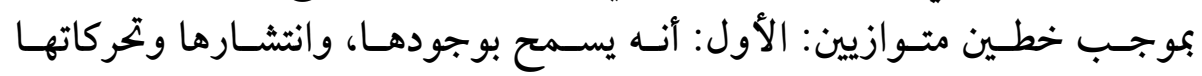

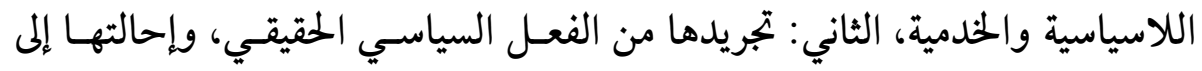

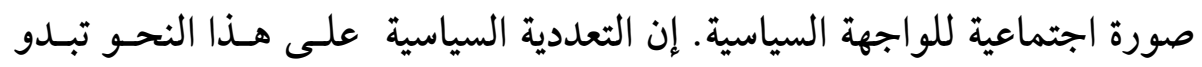

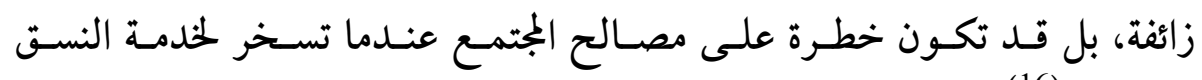
السياسي

وفي هذه الحالة، يبرز المجتمع المدني "الضـار"كواجهـة للـنظم المتسـلطة، إنـه

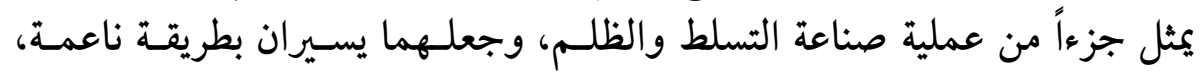




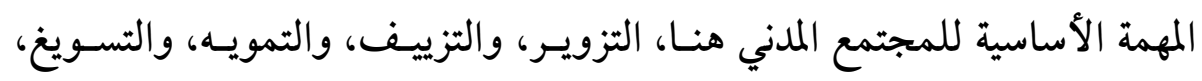

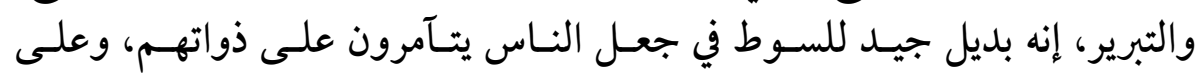
بجتمعاتهم.

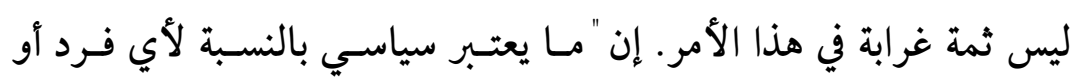

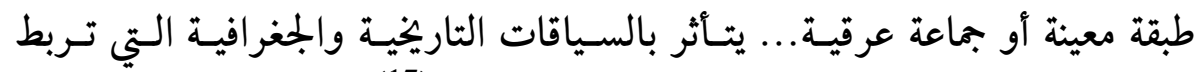

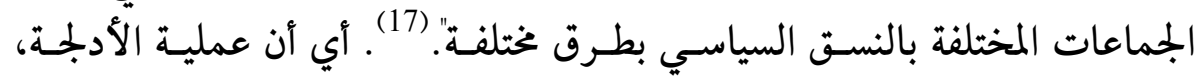

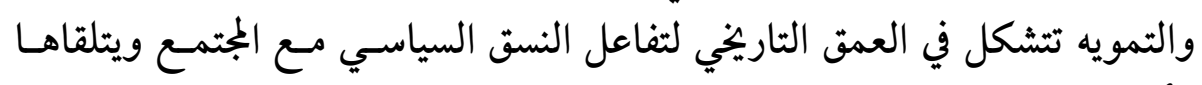

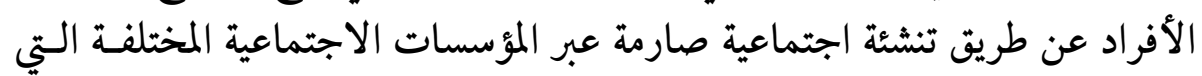

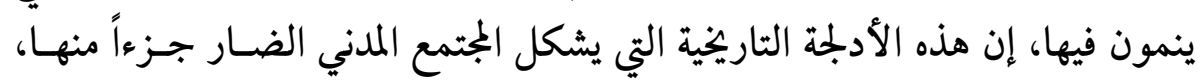

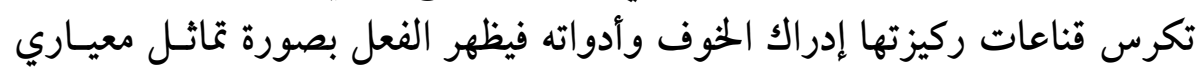

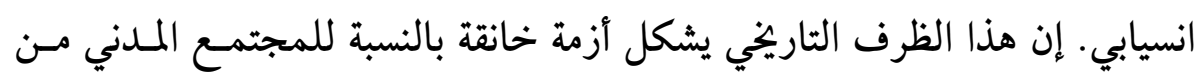

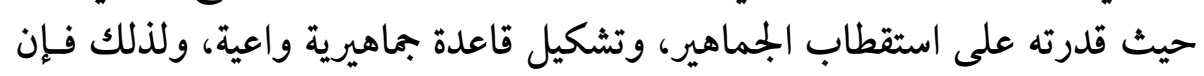

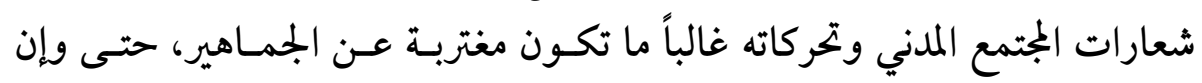
كانت صادقة.

إن افتقاد المجتمع المدني للفاعلية، وافتقاده إلى الاستقطاب الجماهيري يبقي

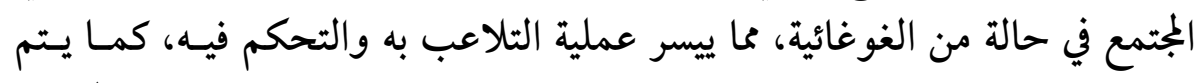

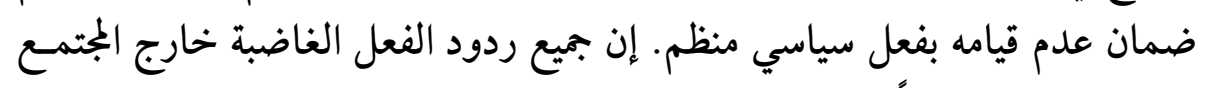

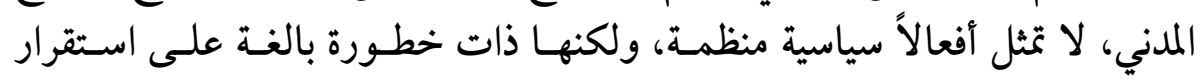

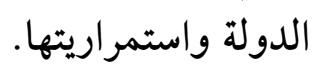

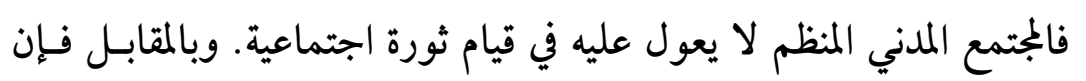

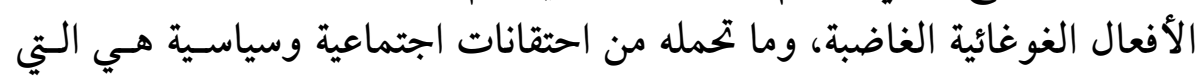

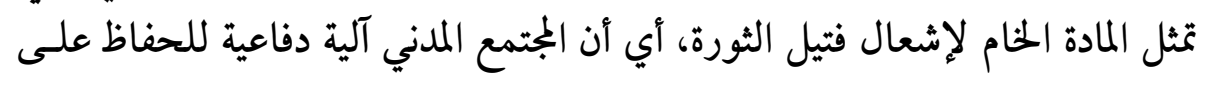

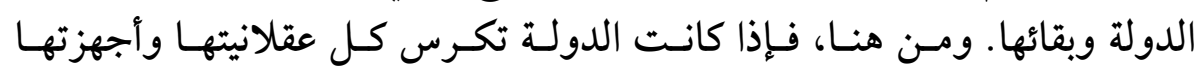
الأيديولوجية لإضعاف المجتمع المدني، فإنها مع ذلك تفتثد إلى "الحكمة السياسية". 
يعمل المجتمع المدني على تنشيط النزعة السياسية للدولة من خـلال مراقبـة

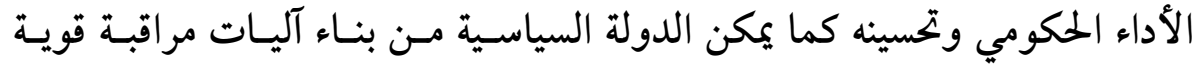

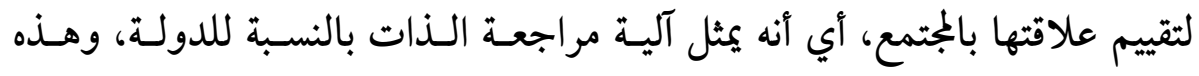

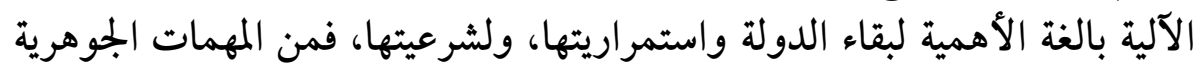

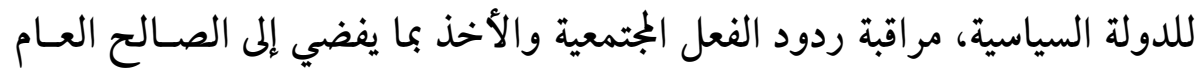

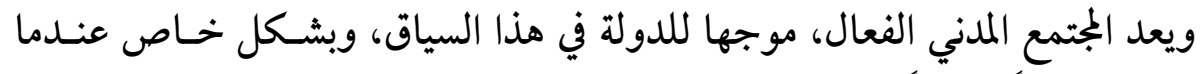

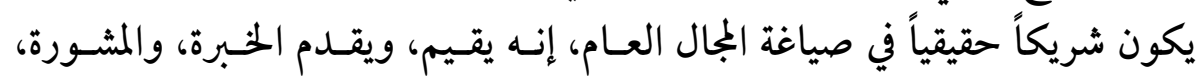

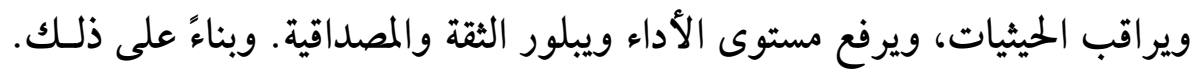

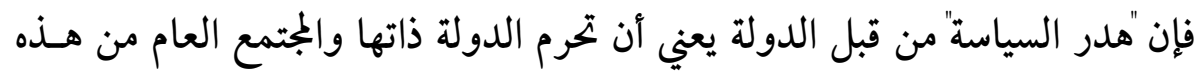

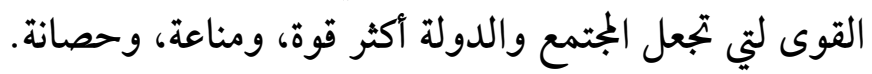

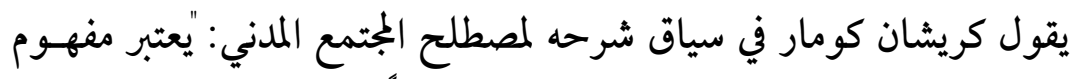

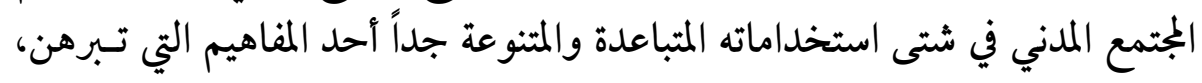

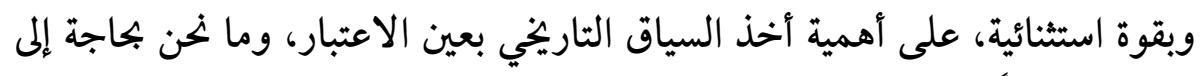

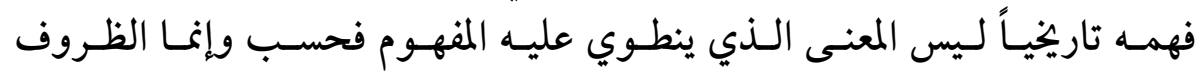

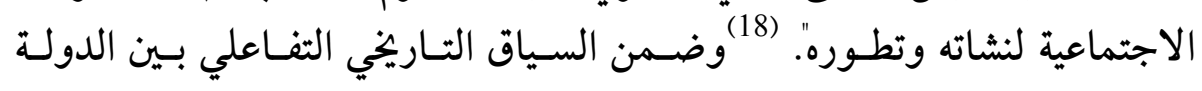

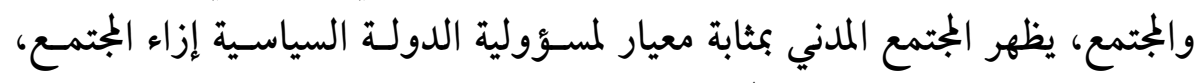

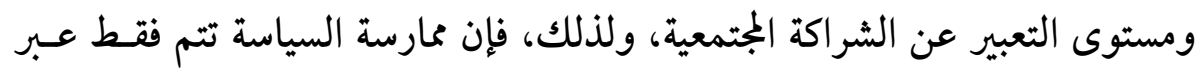

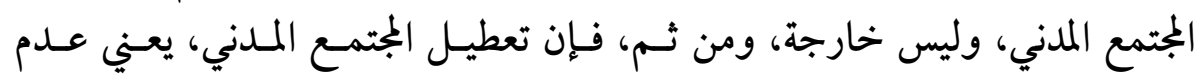

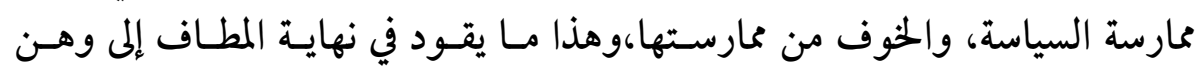
الدولة ووهن المجتمع وبروز جميع مظاهر الشخصية الفاسدة.

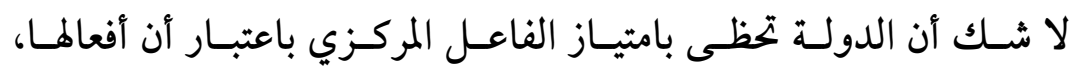

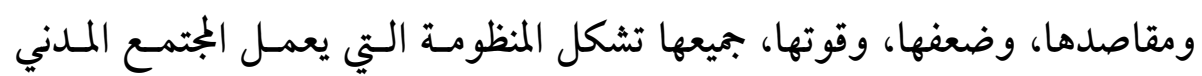

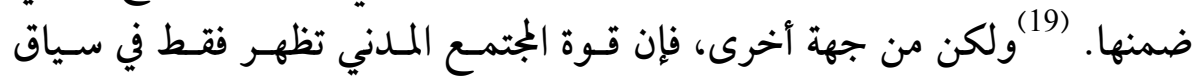

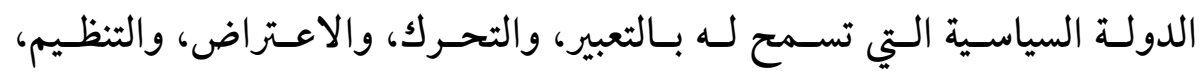

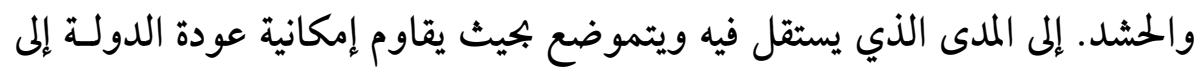


مجلة علوم الإنسان والمجتمع............................................................ محمد عبد الكريه الحوراني

الميمنة. ومن هذا المنطلق تتشـكل إمكانيـة محاسـبة الدولـة وفـق قاعـدة المسـؤولية والمصلحة العامة.

بصورة أكثر وضوحاً، إن مأسسة المجتمع المدني في المجال العـام، تفضسي إلى إلى

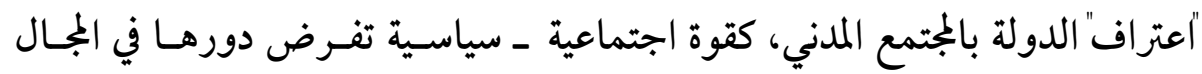

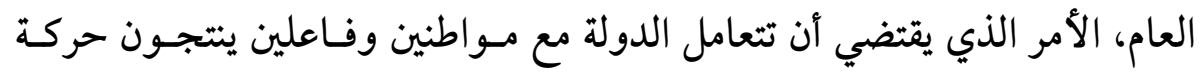

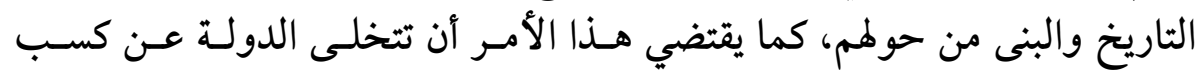

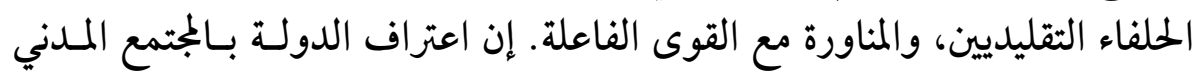

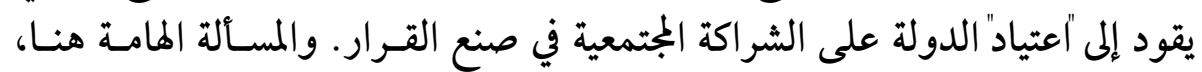

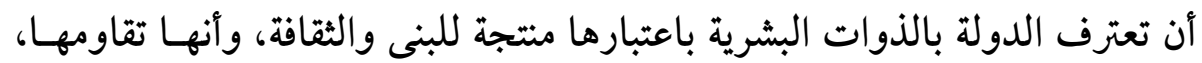

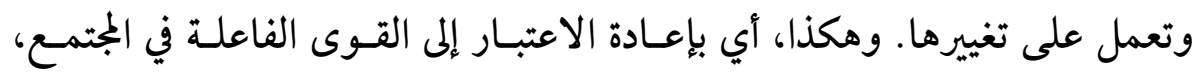
تصل الدولة إلى علاقة "مكشوفة" مع المجتمع تعبر عن أرقى مستوياتها السياسية. ورغم ذلكك، يلاحظظ بـيتر أثزاجـر Houtzager أنـه مـن النـادر أن يقـوم

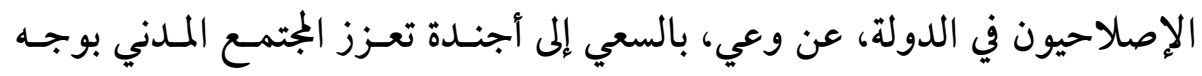

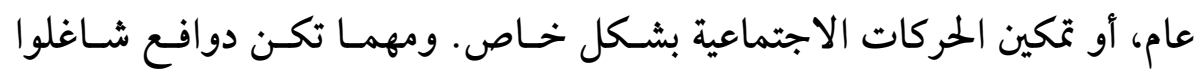

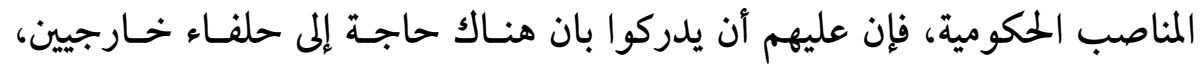

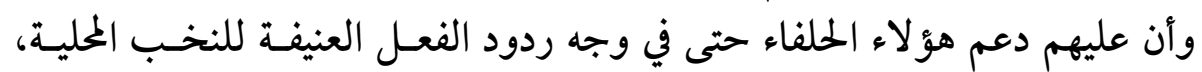

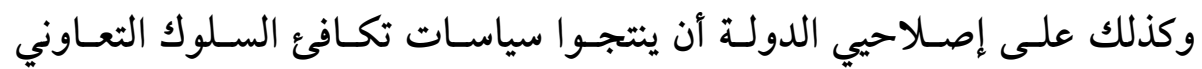

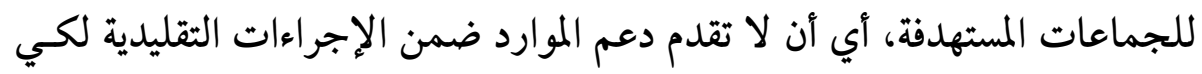

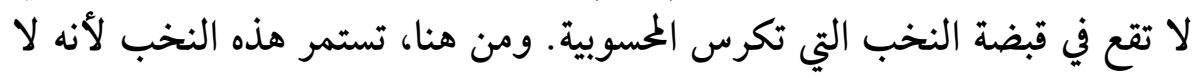

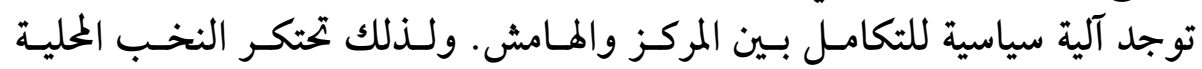
قنوات السمسرة الموجودة وتوزع الموارد من المركز على محاسيبها (20).

إن فكرة الاستثمار السياسي، كما هو واضح، تعبر عن العلاقـة العضـوية

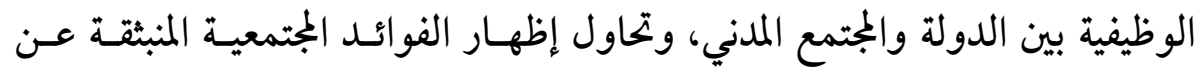

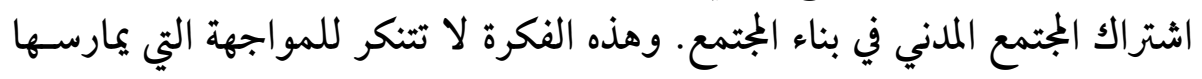

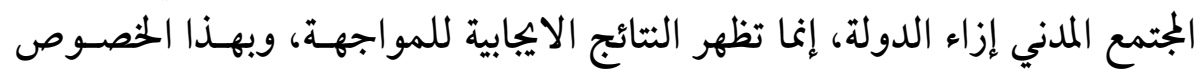


يقول بونس Bounce :"يجب أن لا يتم إظهار المجتمـع المـدني على انسه بجـرد قـوة عدائية ضد الدولة، بل يجب إظهاره كمجال تفاوضي" (21).

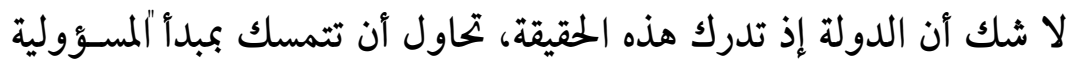

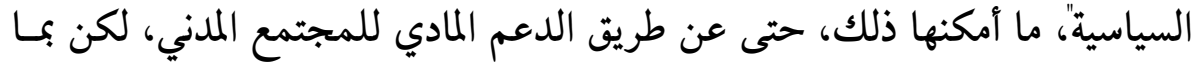

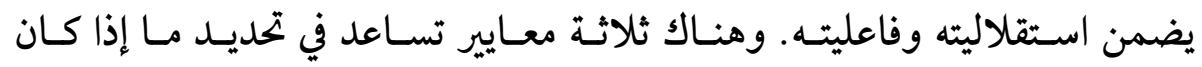

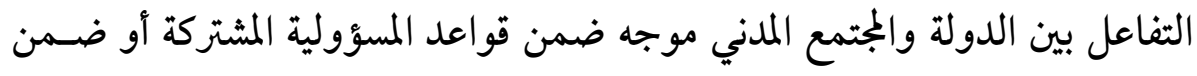

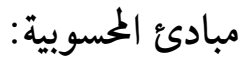

أولأ: اللاشخصانية/ الشخصانية: المعيار الأساسي هنا، مستوى الانفصال عن القيادة.

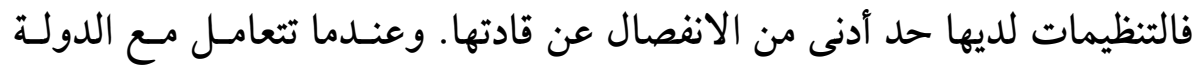

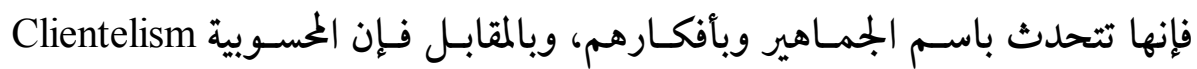

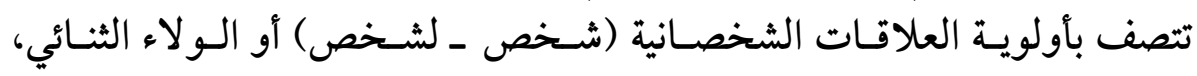

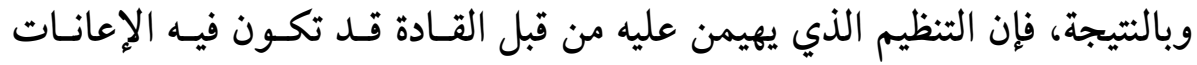
الرسمية بمثابة مكافأة للو لاء الشخصي الذي لذئي عؤديه الألتباع.

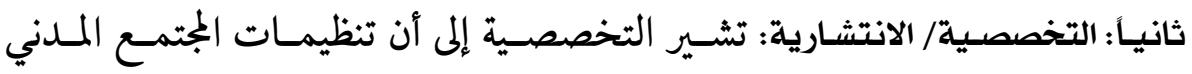

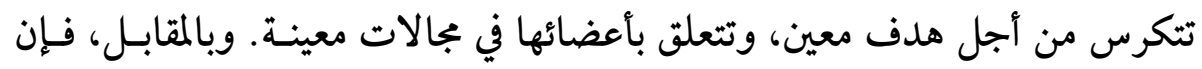

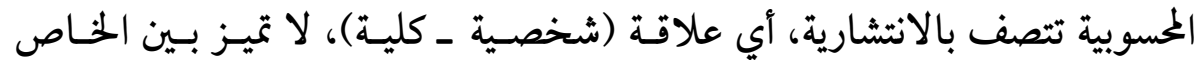
والعام، ولا بين الوجدانية والأداتية.

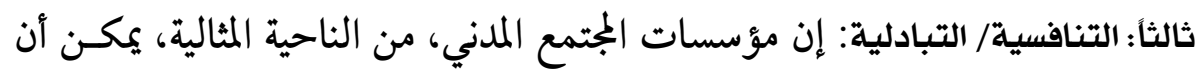

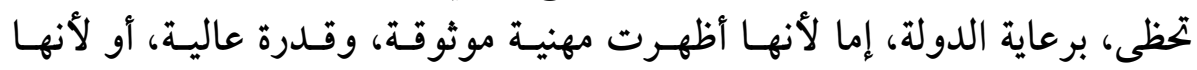

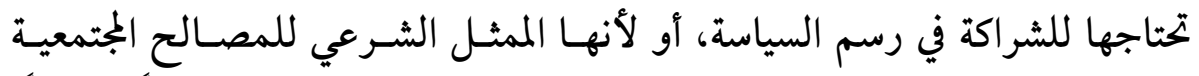

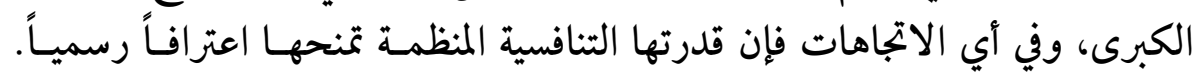

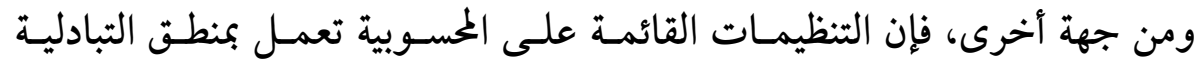

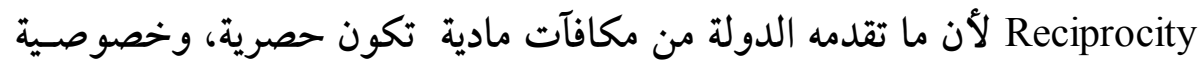


لأشخاص بعينهم، ويترتب على هذا التزام أخلاقي مفـروض على المستفيدين،

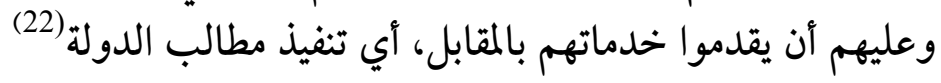

وفي ضوء هذه المعايي، فإن تقديم الدولة، الدعم المادي للمجتمع المدني على المى المي

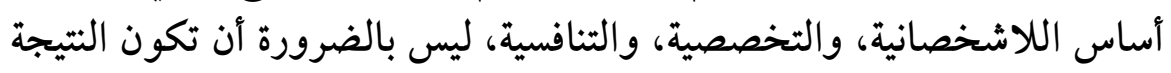

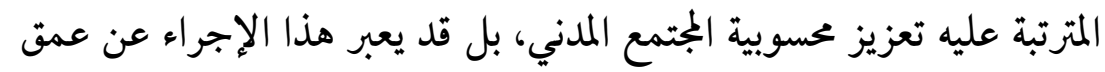

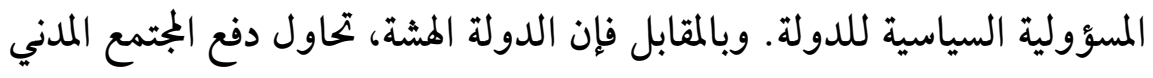
للعمل بمعايير المحسوبية (الشخصانية، والانتشارية، والتبادلية).

(1) شكل

الاستثمار السياسي

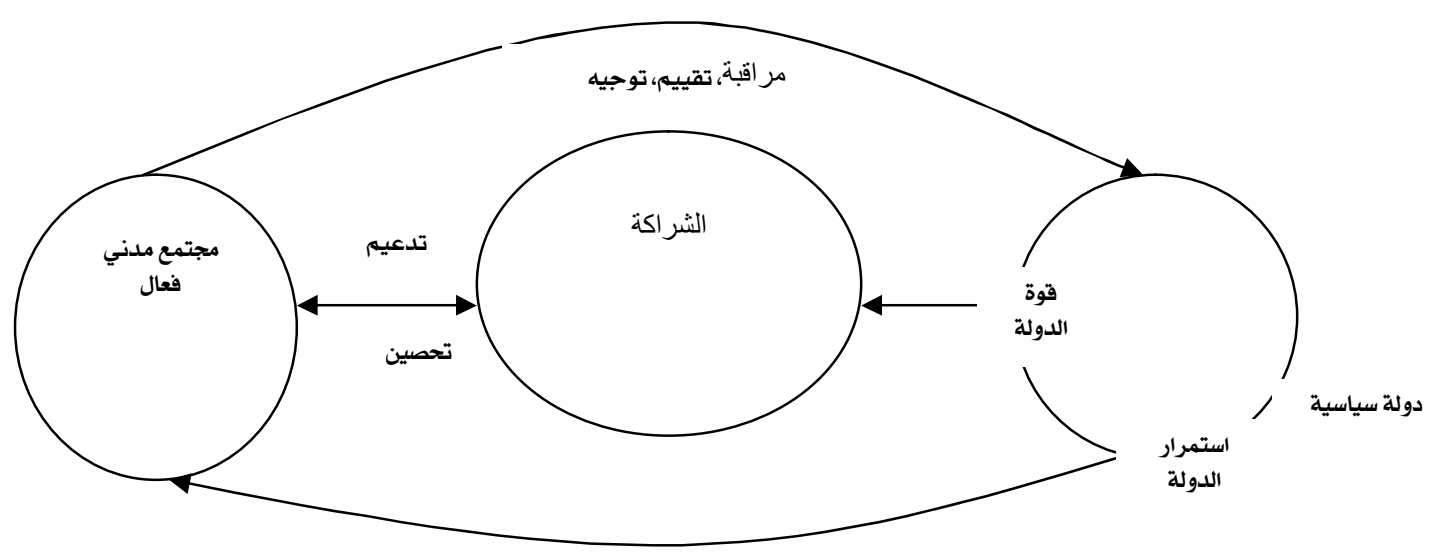

مسؤولية سياسية

استثمار رأس المال السياسي 


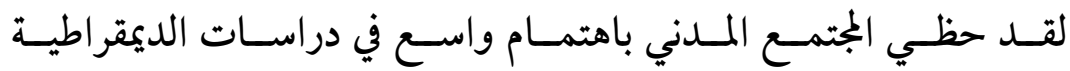
والدمقراطة، وقد أظهرت الدراسات قدرة المو اطنين العاديين الذين يعملون خـارج

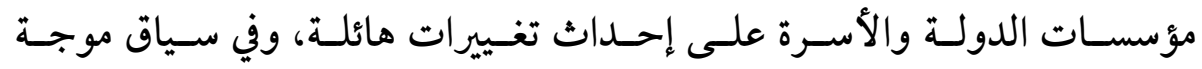

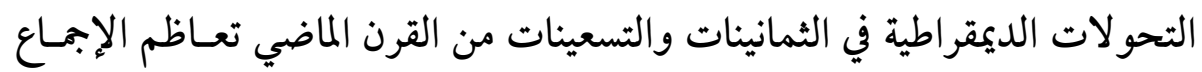

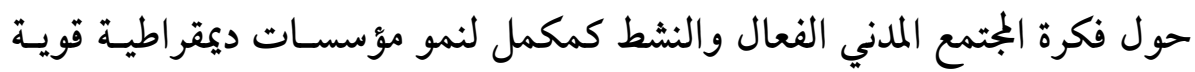
وفعالة (23).

وكما يلاحظ روبـرت بوتنـام: لقـد ظلـت محسددات الديمقراطيـة تسـاؤلاً

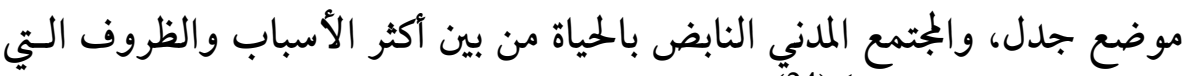

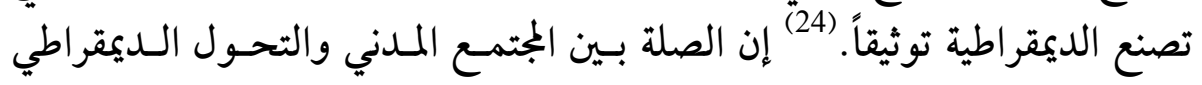

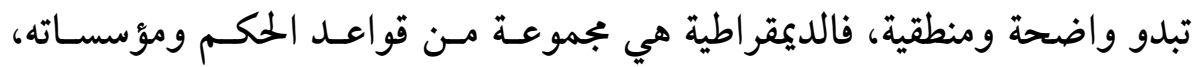

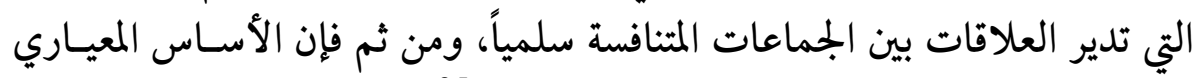
للمجتمع المدني هو الأساس المعياري للديمقراطية (25).

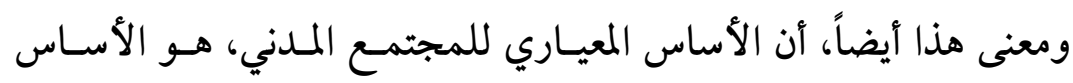

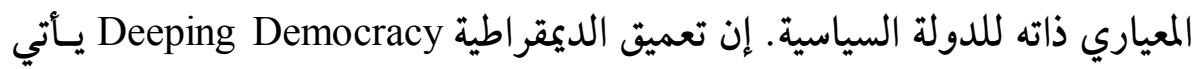

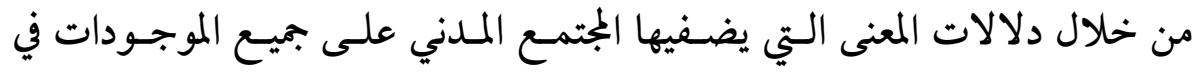

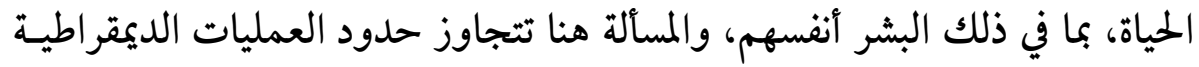

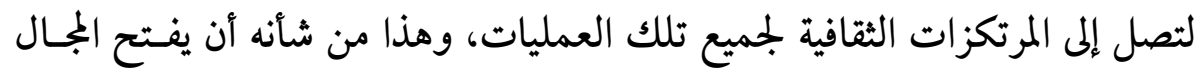

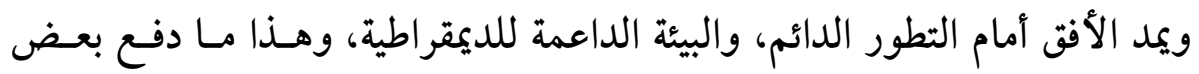

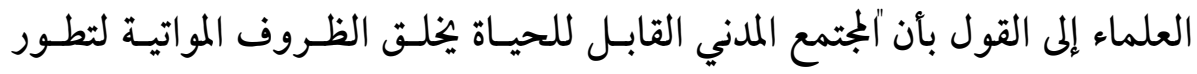

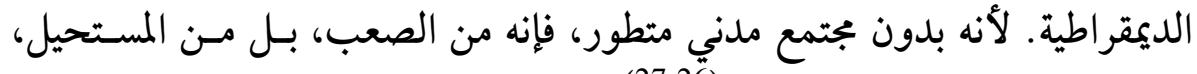

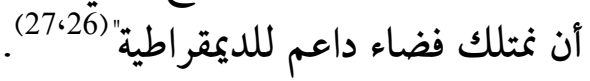

وكذلك تتجاوز المسالة هنـا، حـدود الديمقراطيـة الانتخابيـة إلى مضــاعفة

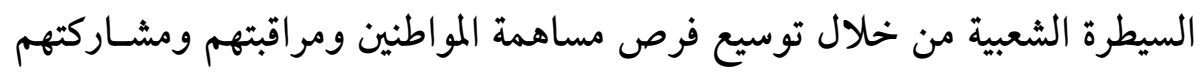


بشكل مباشر (28) .وهذا يعني تأسيس أطر للمعنسى تمـنح المـواطنين إمكانيـة ممارسـة

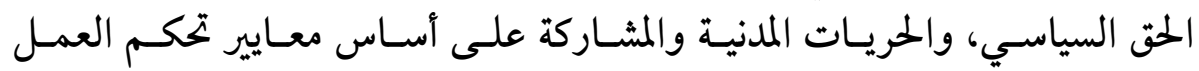

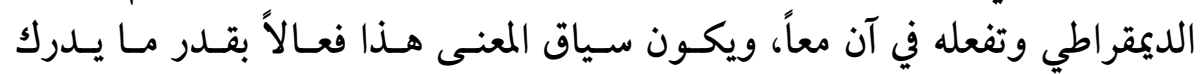

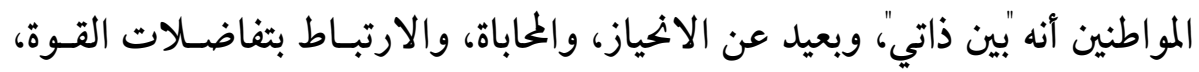

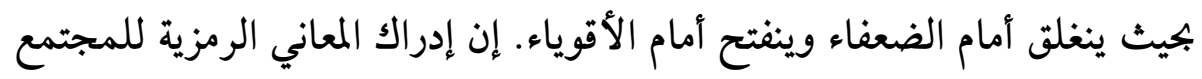

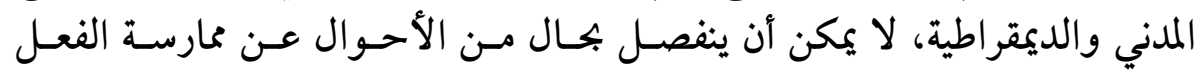

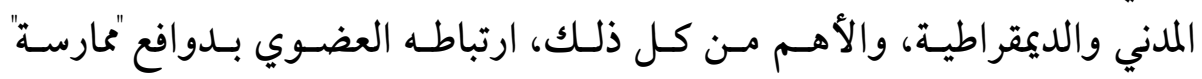
الديمقراطية.

وهكذا، يكتسب الفعل المدني طابعاً عقلانيـاً يتجـاوز حسدود الإشـباعات

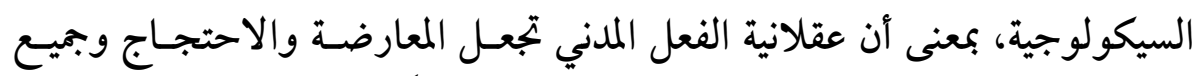

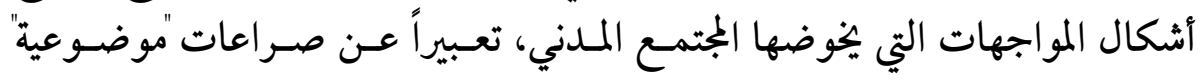

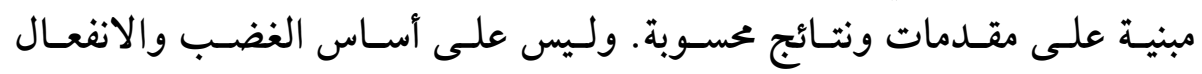

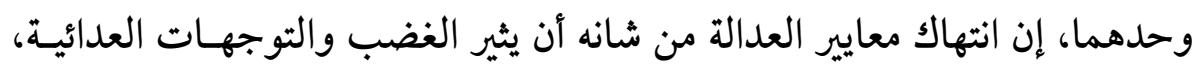

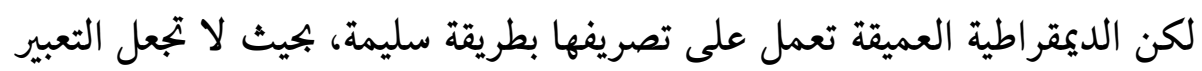

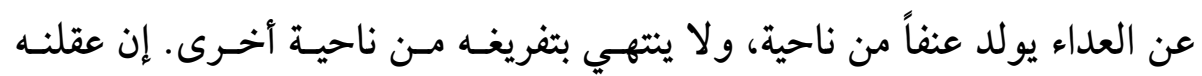

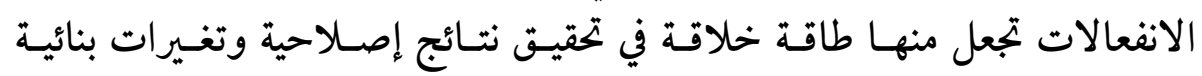
عميقة. لا تخدم السيكولوجية الفردية بقدر ما تخدم المصلحة العامة.

فتجاوز هـــه الأطروحـة بعضض التفسـيرات السوسـيولوجية الكلاسـيكية

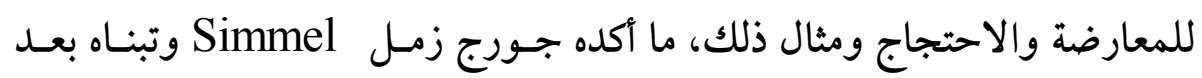

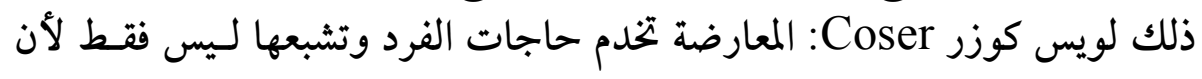

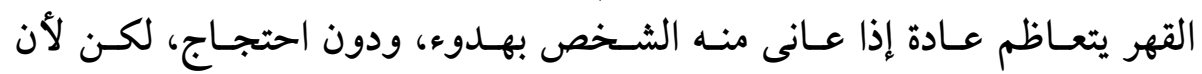

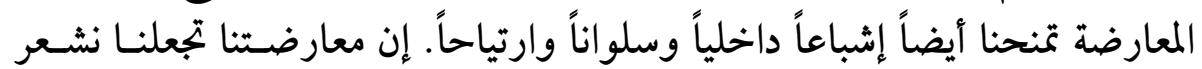
بأننا لسنا ضحايا لظروف عامة. (29)

وبناءً على ذلكـ، فـإن احتفــاظ الدولـة بمؤسسـات الديمقراطيـة الليبراليـة

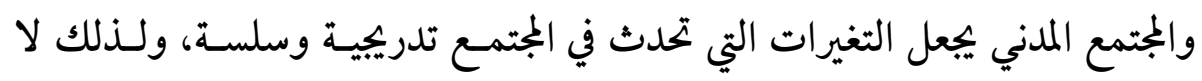




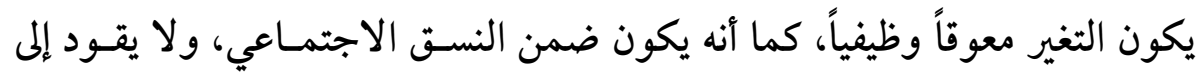

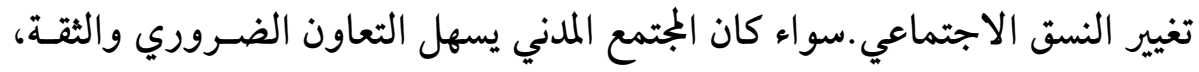

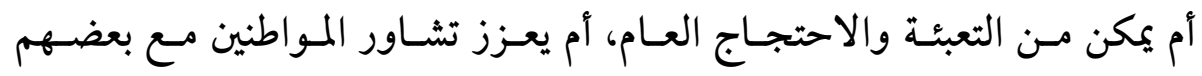

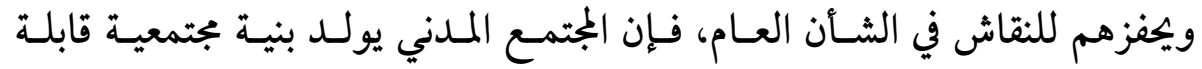

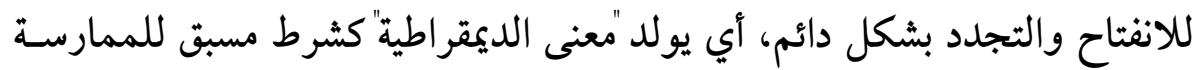

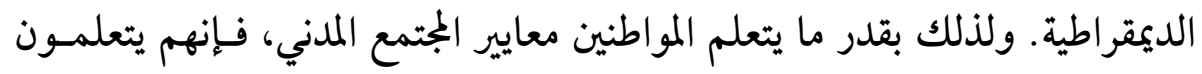

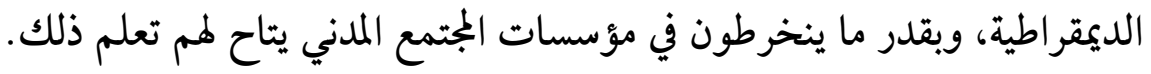

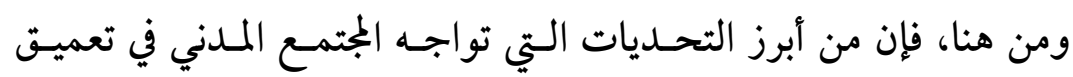

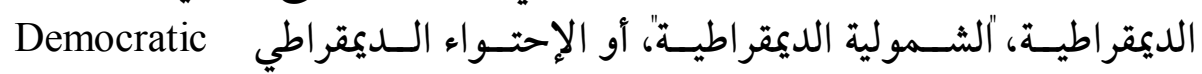
وأتxclusivity

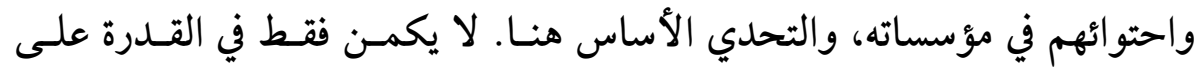

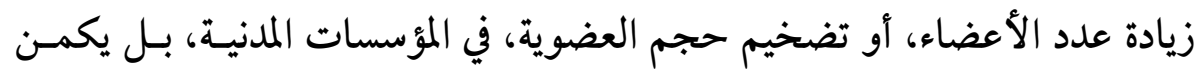

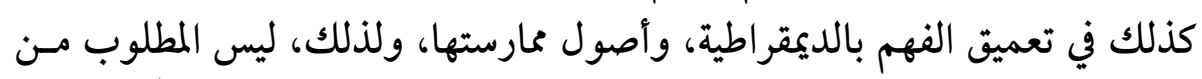

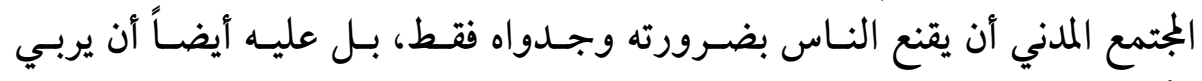
الأعضاء على ممارسة الثقافة المدنية التي تجسد رّورح الديمقراطية.

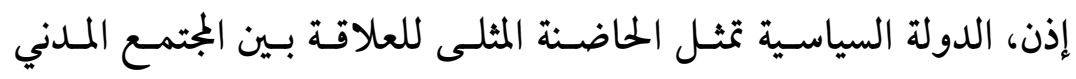

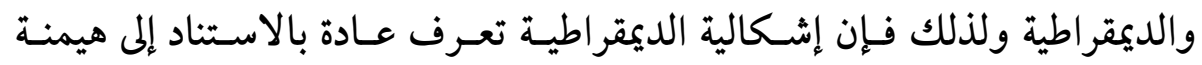

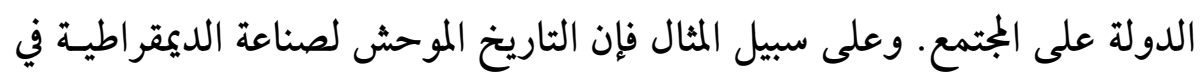

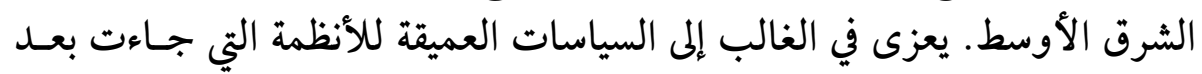

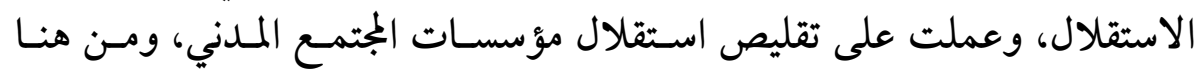

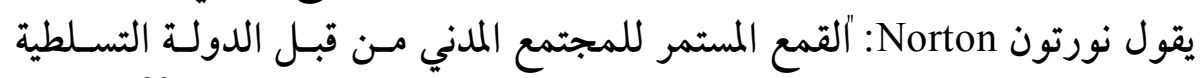
يعتبر الظرف الأساسي والأكثر شيوعاً واستمرارية في إعاقة الديمقراطية (30).

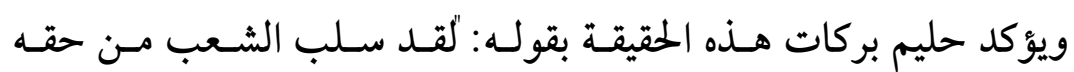

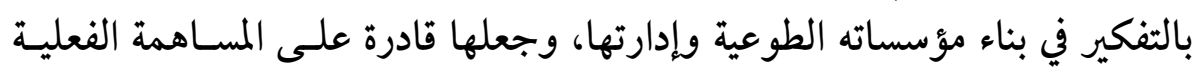

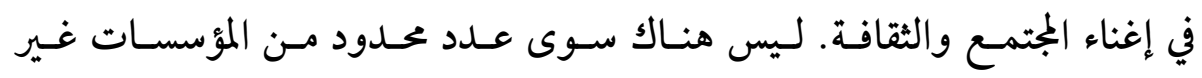


الحكومية، وحيث توجد ينتهي الأمر بوقوعها تحت نفـوذ القـوى المتحكمـة بكسير

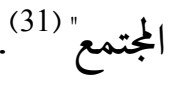

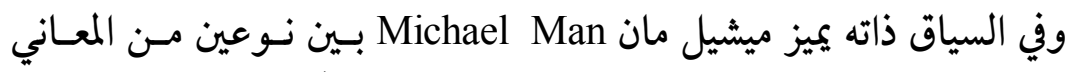

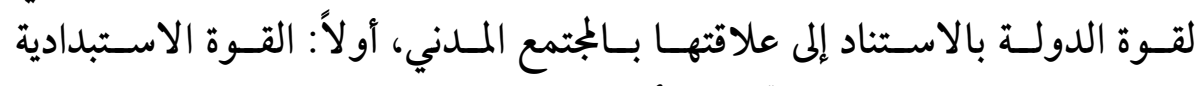

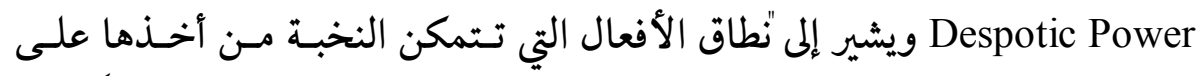

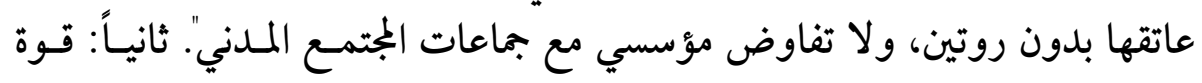

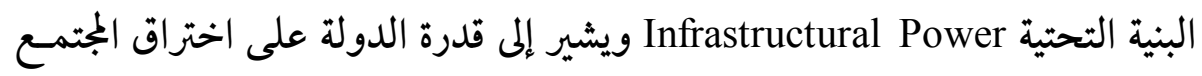

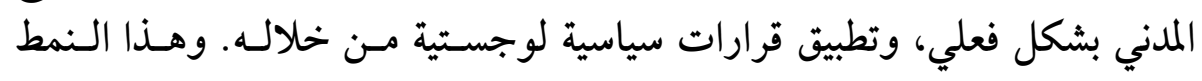

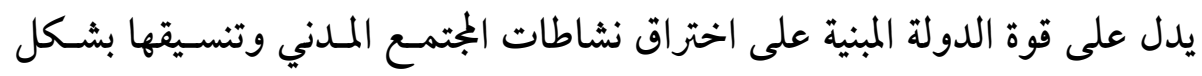

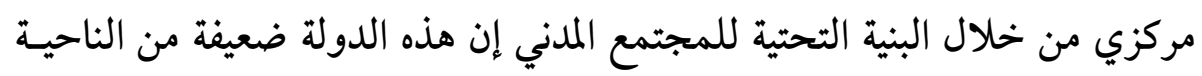

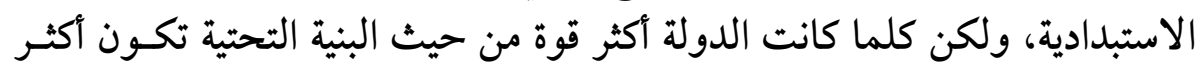

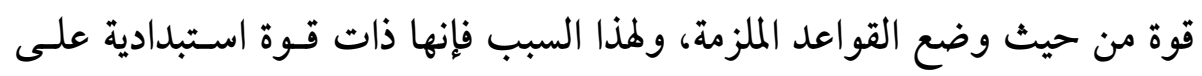

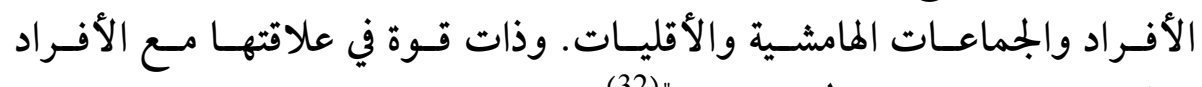
والجماعات الضعيفة في المجتمع المدني" (32).

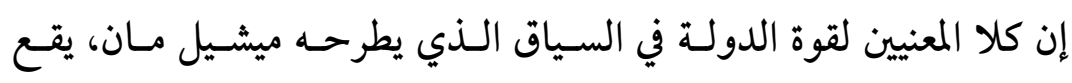

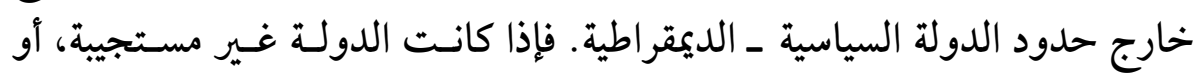

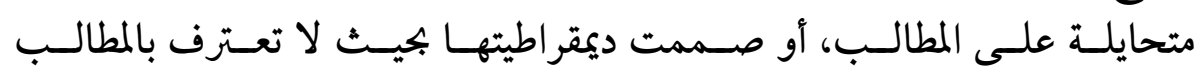

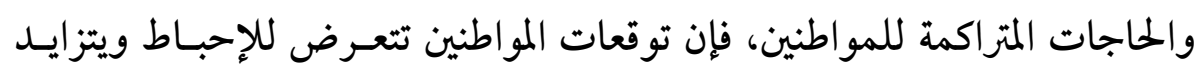

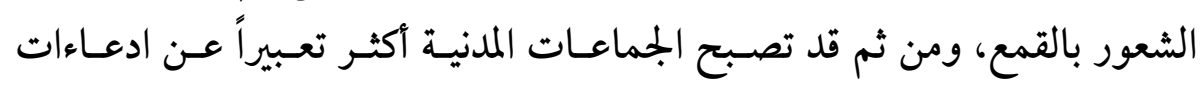

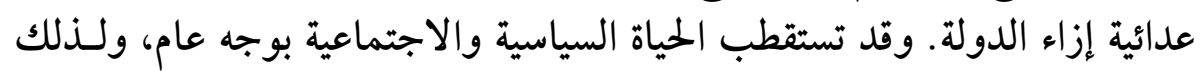

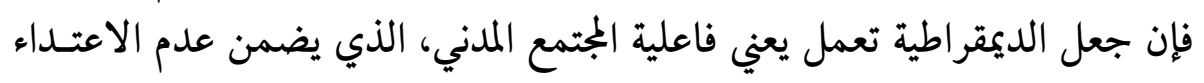

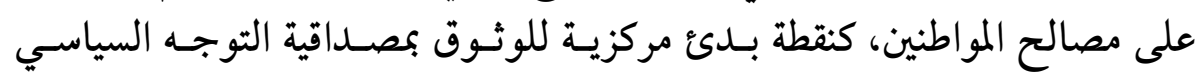

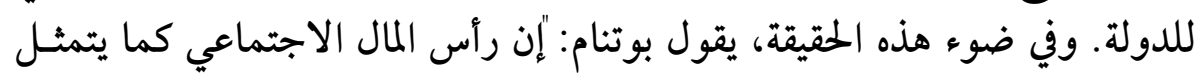

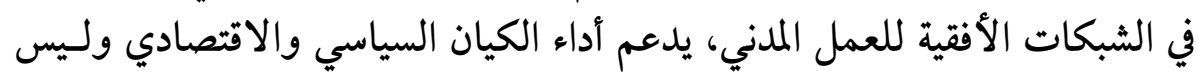


قاية" العكس، فالمجتمع القوي يؤدي إلى اقتصاد قـوي. والمجتمـع القـوي يـؤدي إلى دولــة

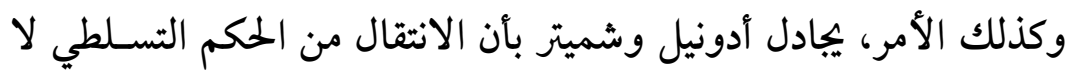

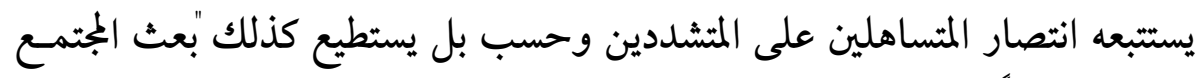

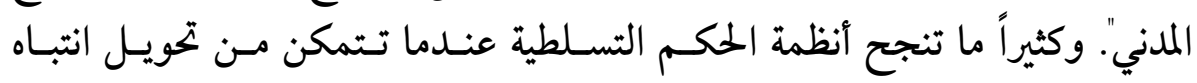

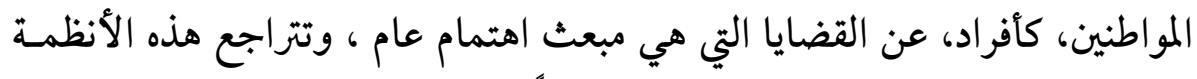

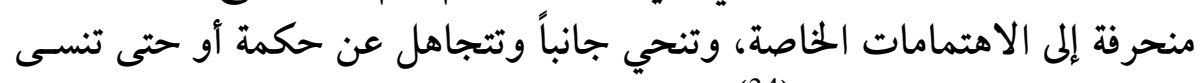
هوياتها العمومية والسياسية (34).

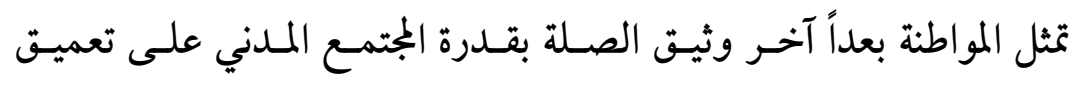

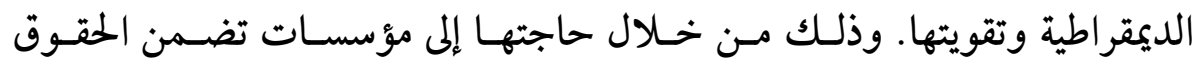

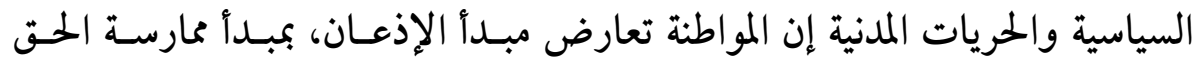

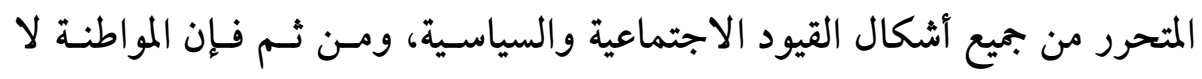

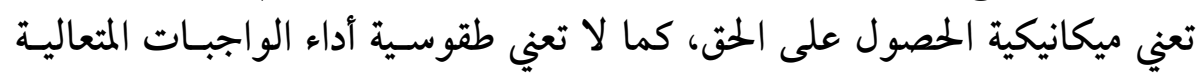

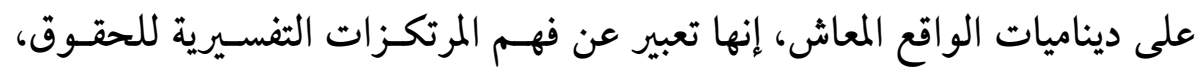
والواجبات، والوعي الجلدلي الذي يعكس العلاقة بينهما.

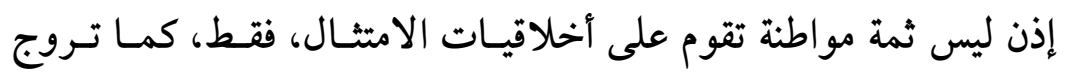

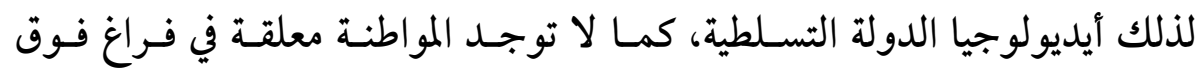

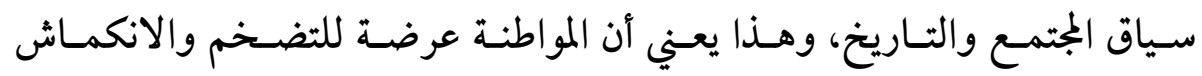

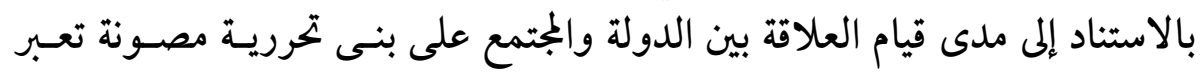

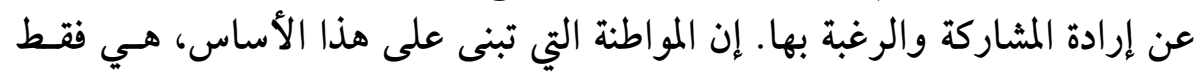

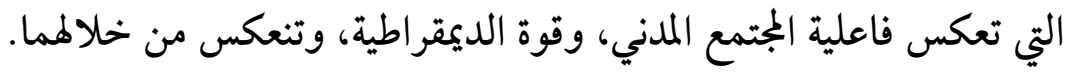

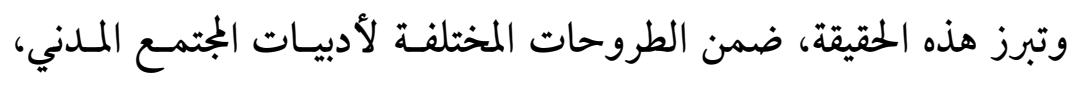

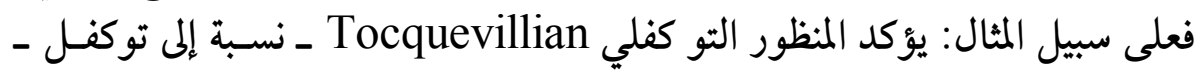

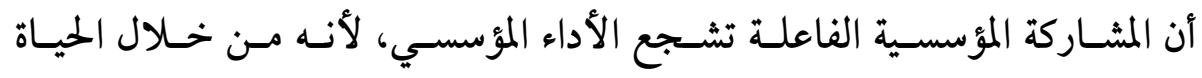




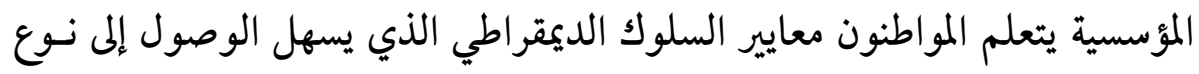

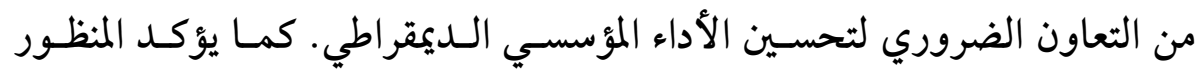

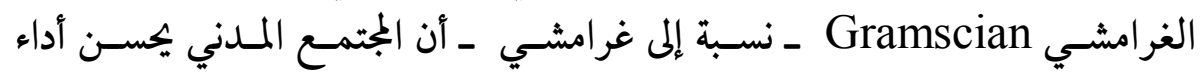

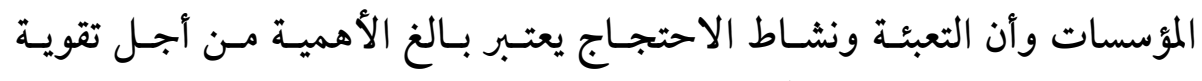

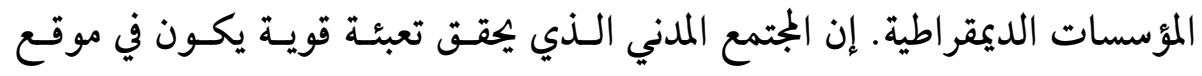

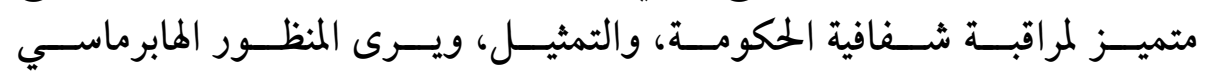

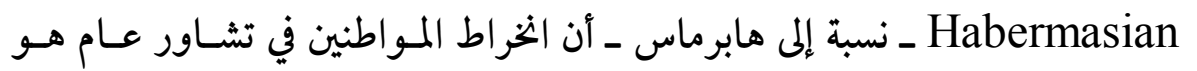

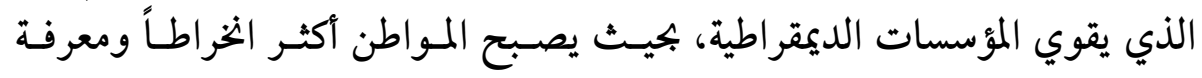

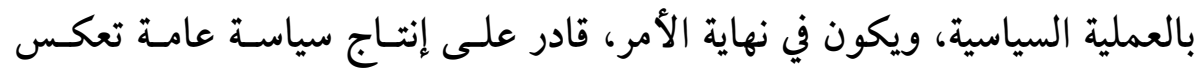

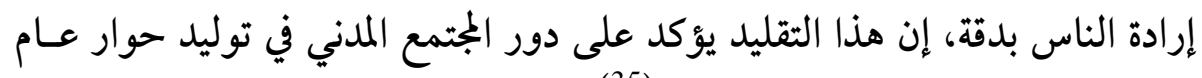

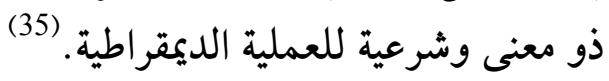

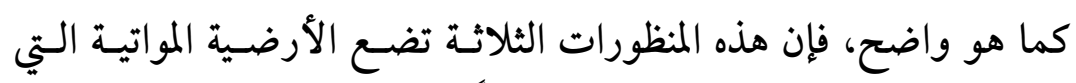

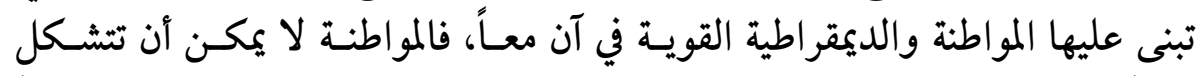

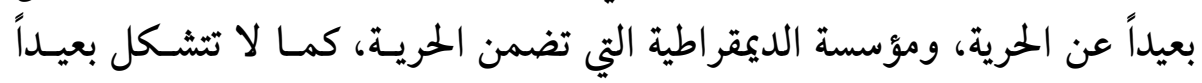

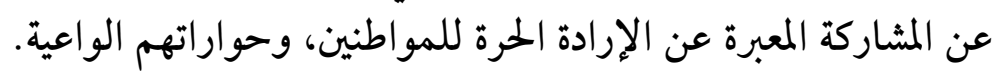

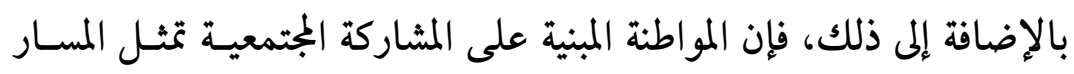

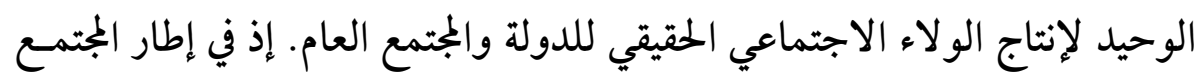

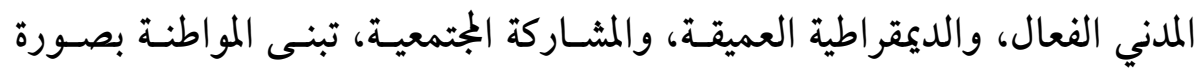

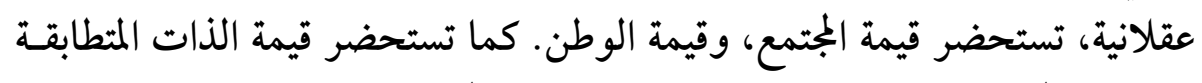

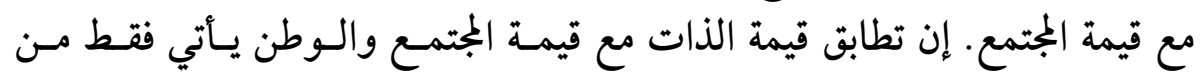

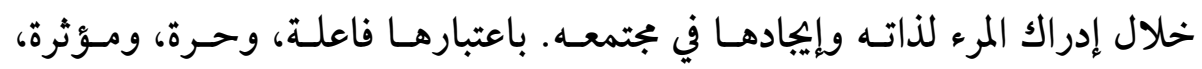
ومصانة الحقوق.

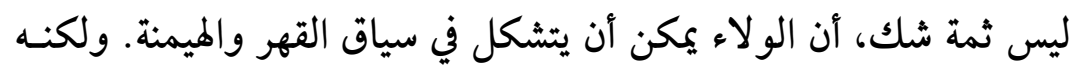

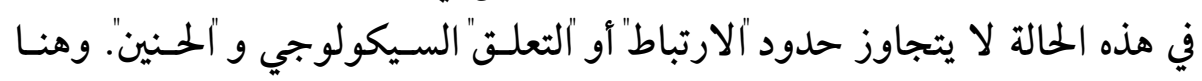

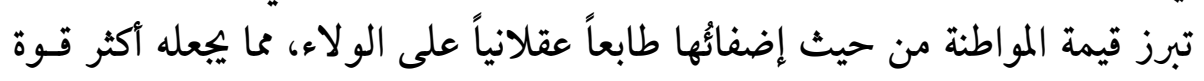


وجوهرية. كما تبرز قيمتها من خلال إظهارها الارتباطـات الوثيقـة بـين المشـاركة المجتمعية وحضور مفهوم الكل الاجتماعي والوطن في ثقافة المـواطنين ومنارسـتهم.

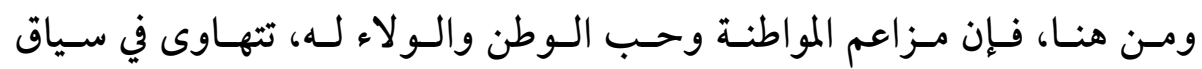

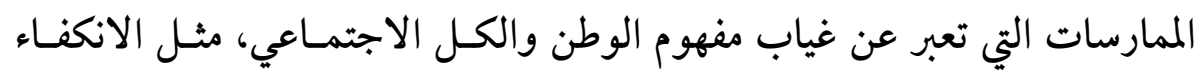

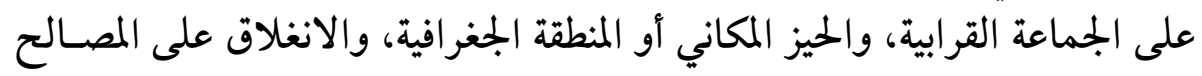
الخاصة.

ومسن هنـا، اقتضـت سـلطوية الدولــة العربيـة وهيمنتهــا تجـزيء الكــل

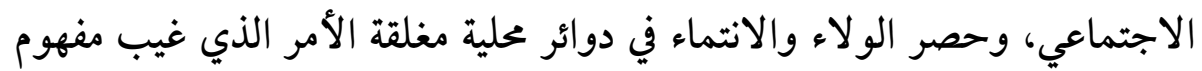

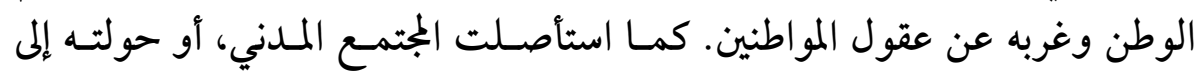

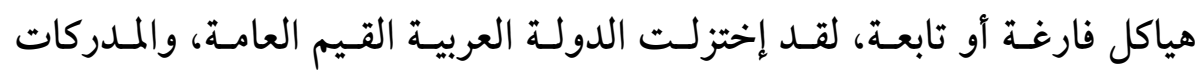

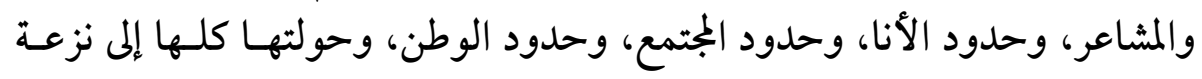
سيكولوجية استبعادية.

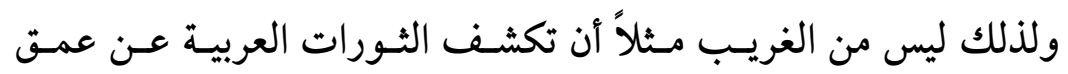

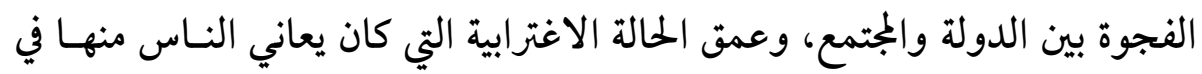

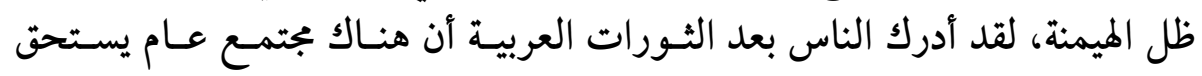

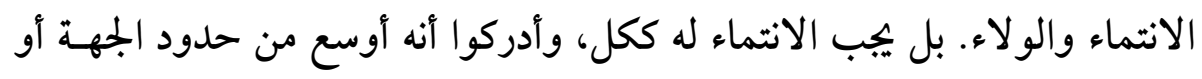

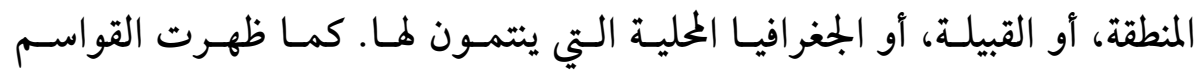

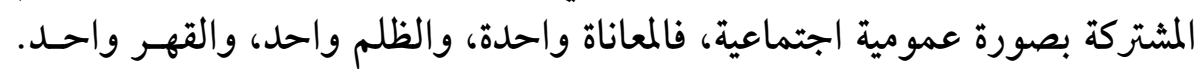

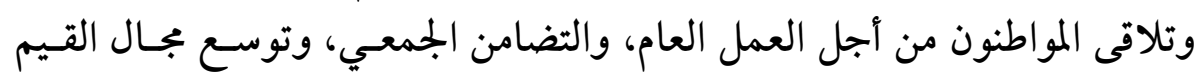

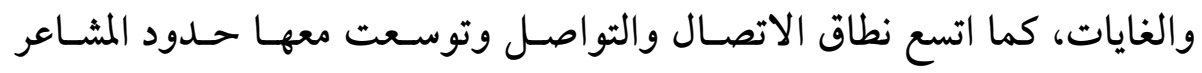

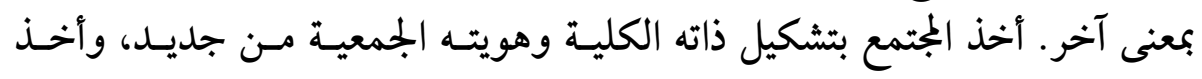

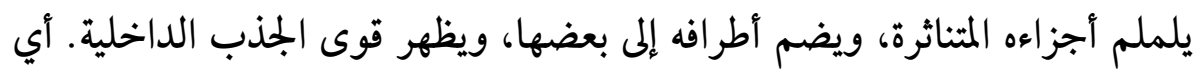

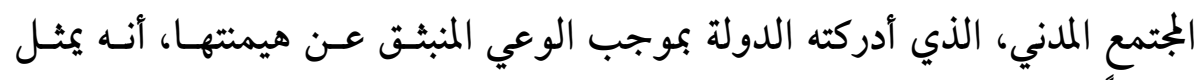
تهديداً لها. 


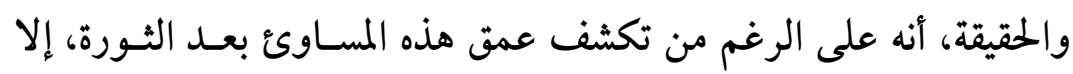

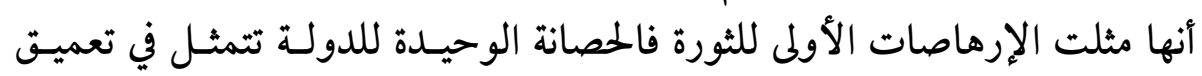

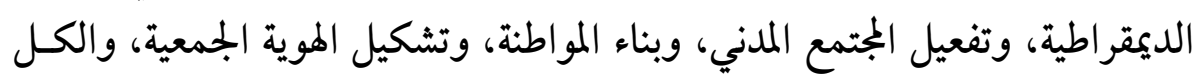

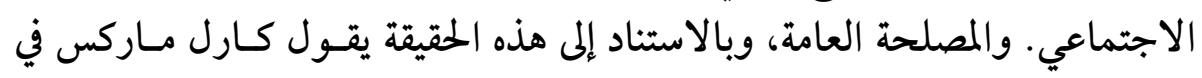

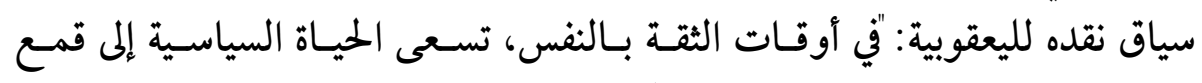

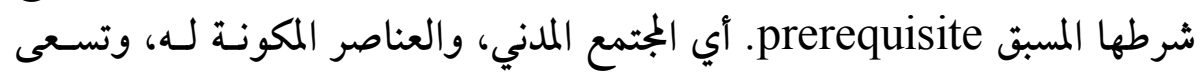

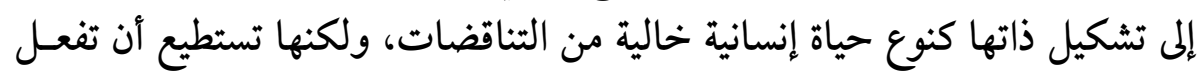

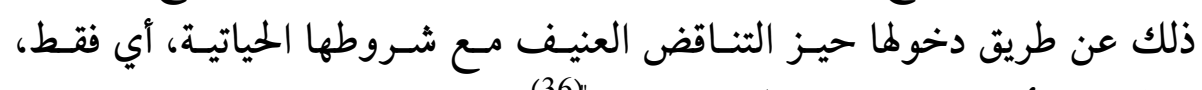
بإعلانها وتاكيدها استمرارية الثورة وقيامها، (36).

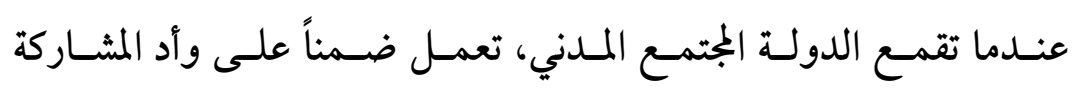

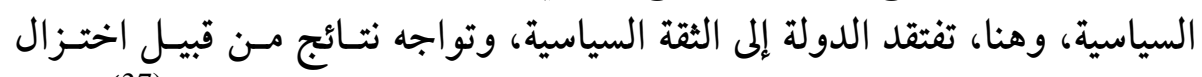
الامتثال الطوعي للمواطنين، ورفض القادة وعدم الاتفاق مع سياساتهم. (37).

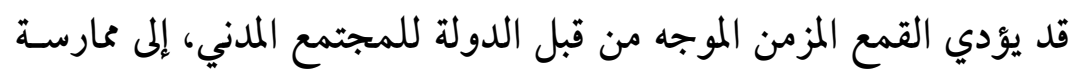

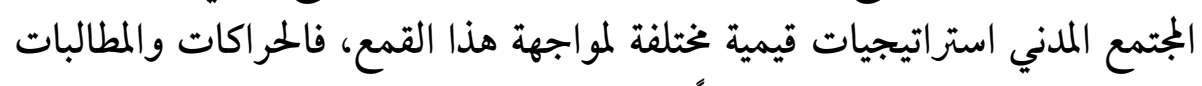

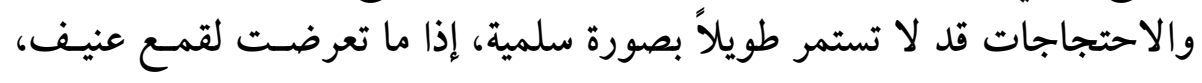

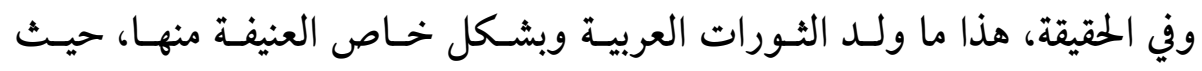

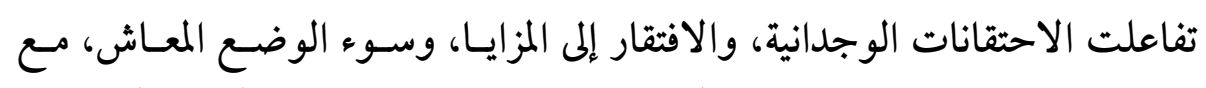

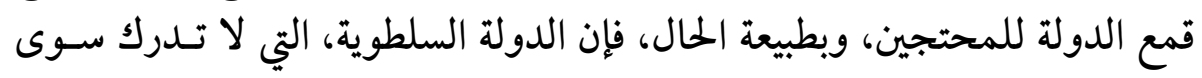

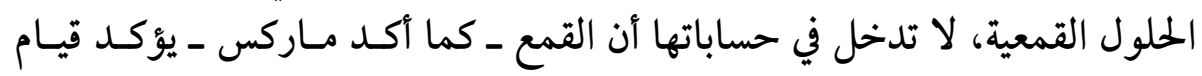

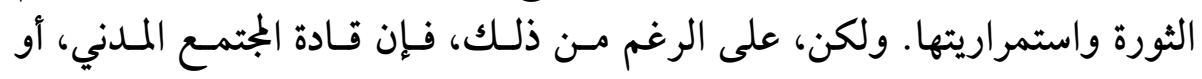

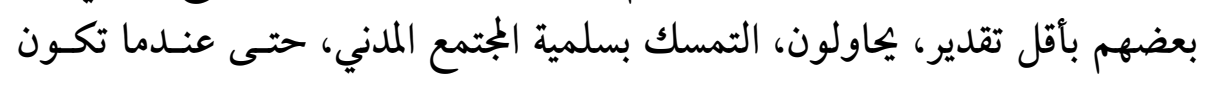

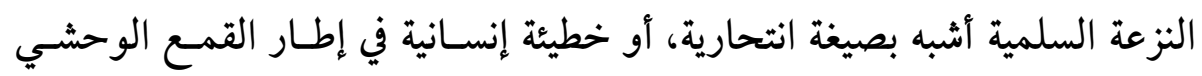
للدولة.

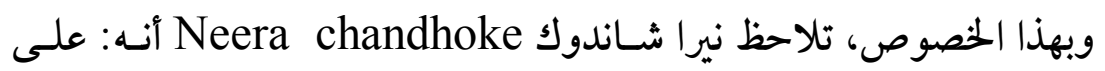
الرغم من حقيقة أن المجتمع المدني يستخدم فقط وسيأل فئل غير عنيفة للاحتجاجـات، 
والتظاهرات السلمية، والإضرابات، ورفع العرائض، وهي جميعها مسـموح بهـا في إحتي

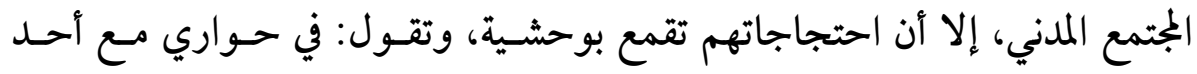

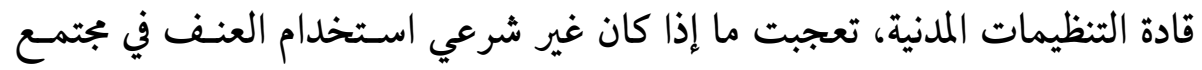

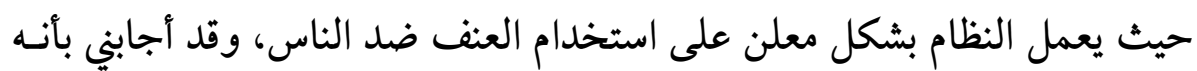

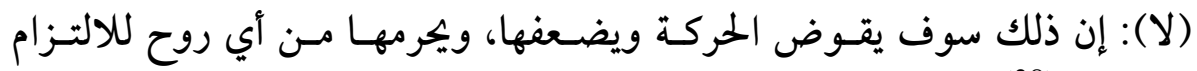
الأخلاقي (38). (الان ذلك

\section{شكل (2)}

\section{(تعميق الديمقراطية)}

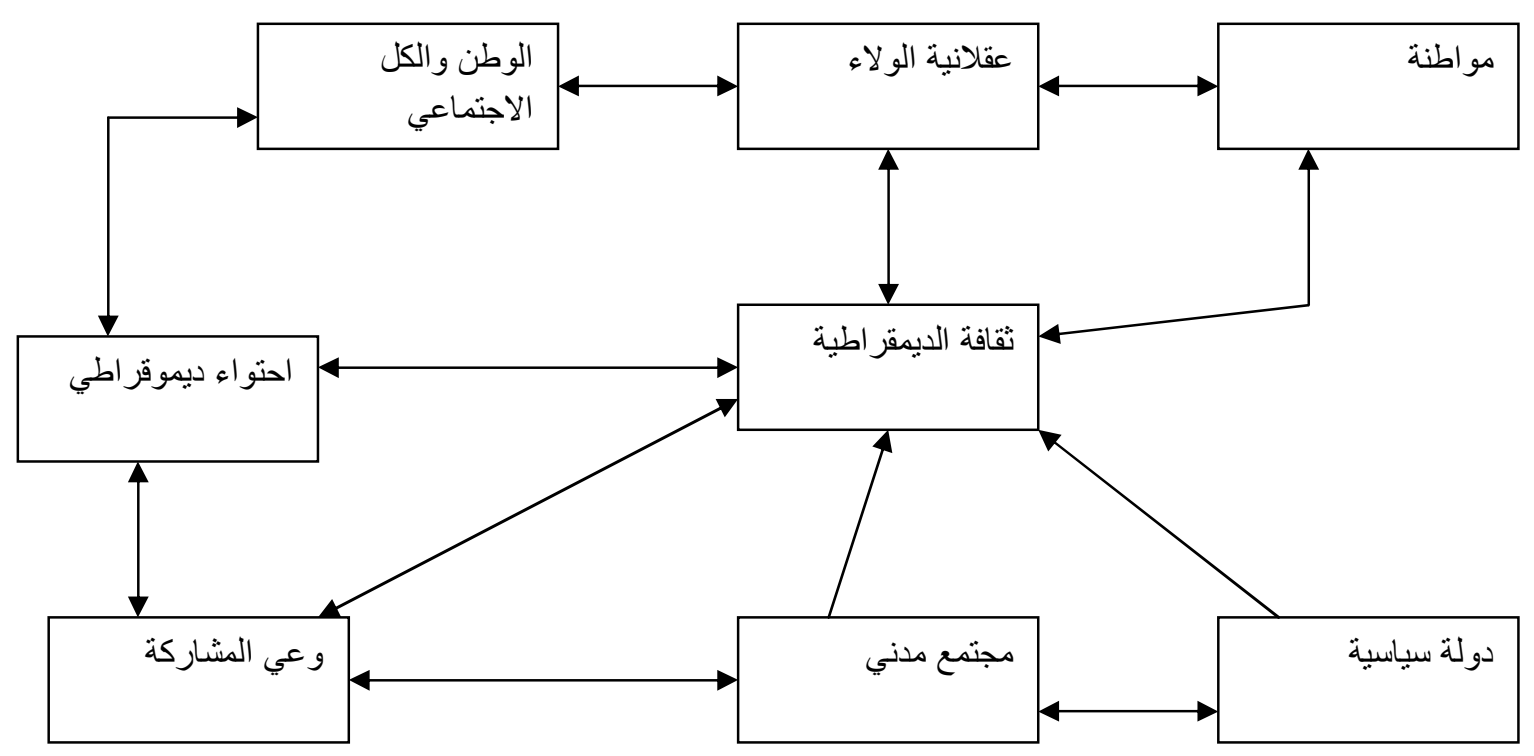

$$
\text { بناء الشرعية }
$$

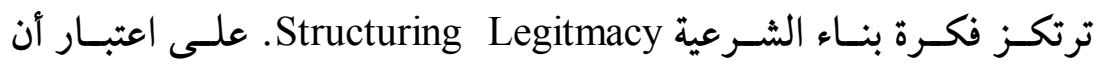

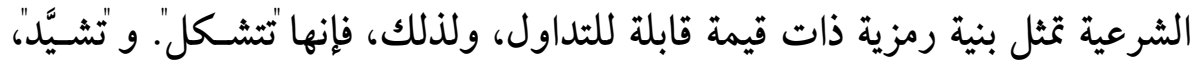

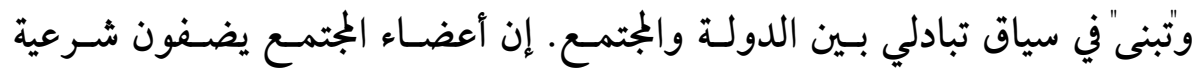


(استحقاق النظام السياسي الاعتراف به) على النظام السياسي مقابـل إخلاصـه في

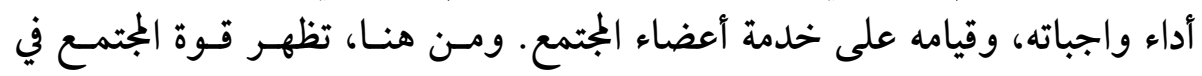

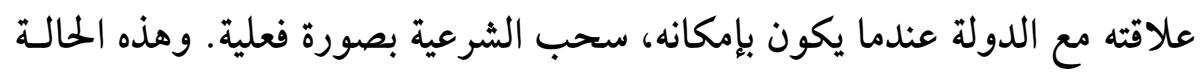
لا تتحقق إلا بجضور المجتمع المدني المنظم والفعال.

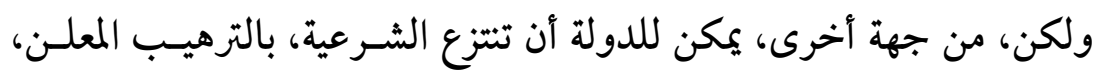

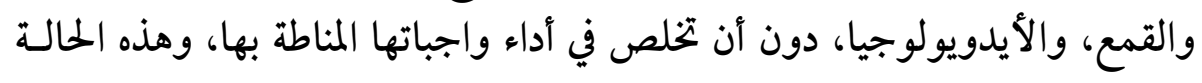

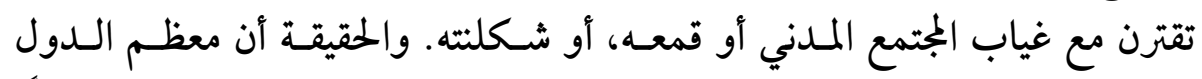

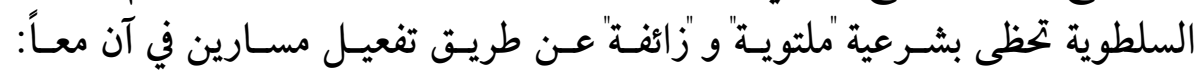

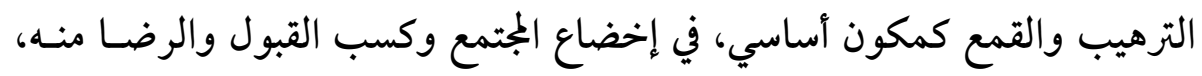

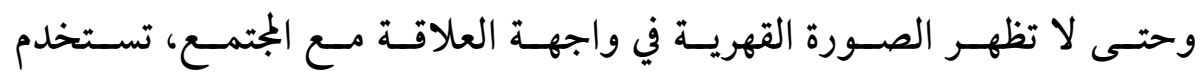

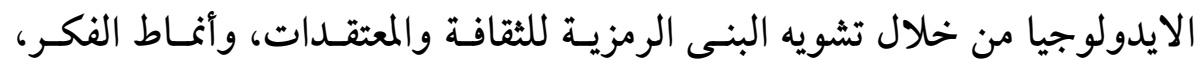

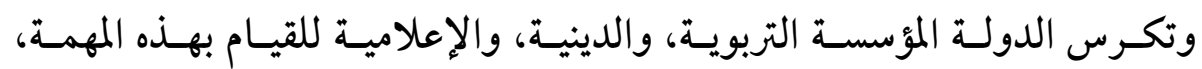

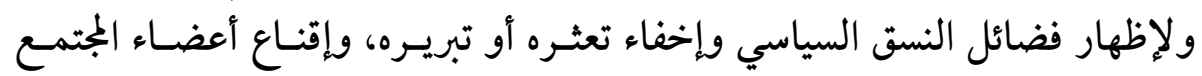
بضرورة تعميق الولاء والانتماء، وتقديم الطاعة.

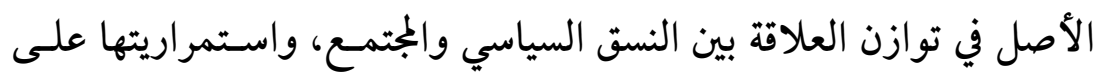

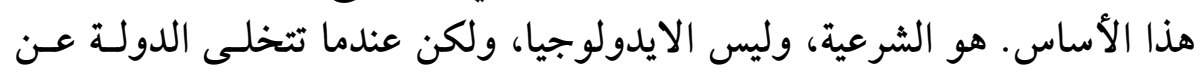

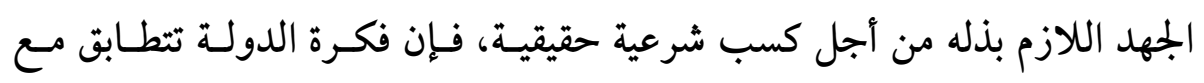

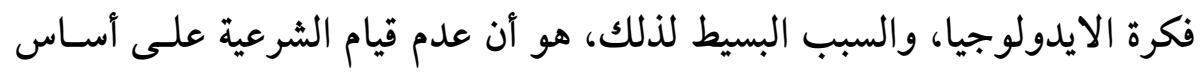

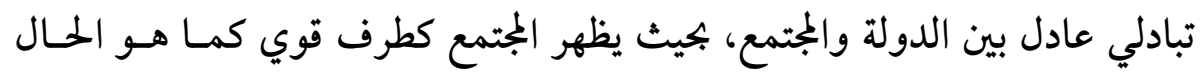

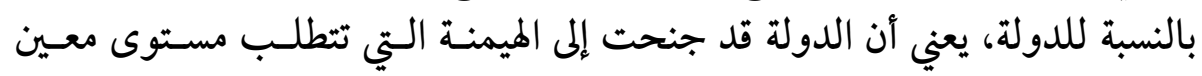

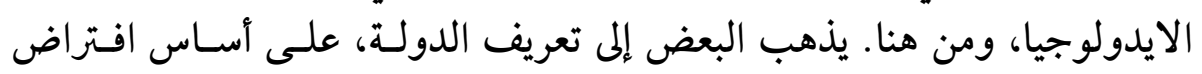

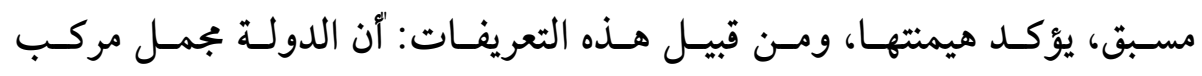

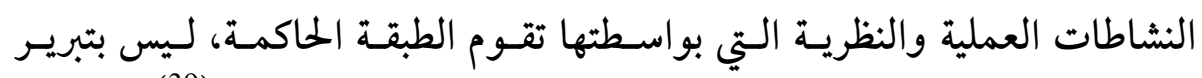

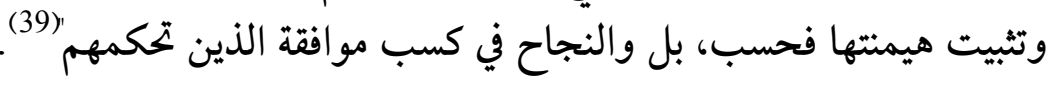




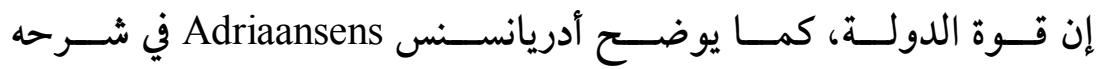

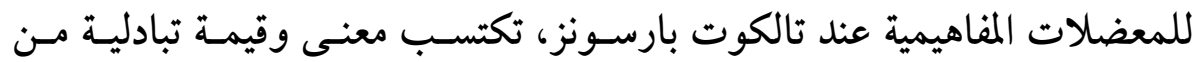

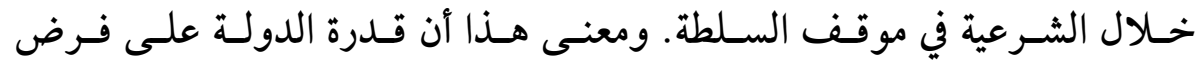

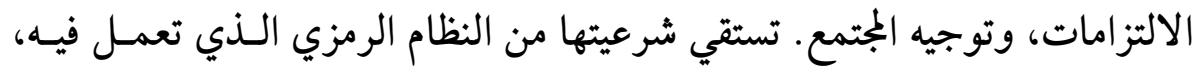

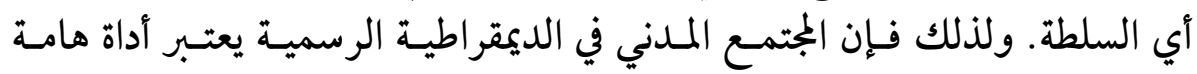

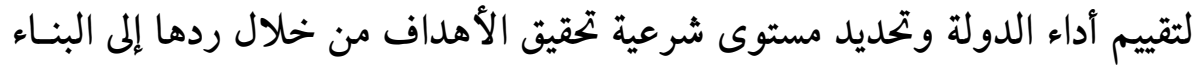

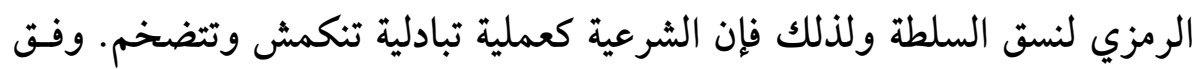

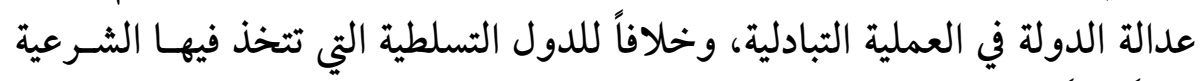

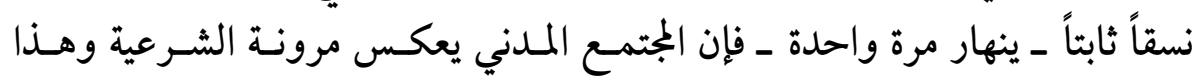
تعبير عن مرونة المجتمع وديناميته (40).

وعلى هذا النحو، فإن الجذور العميقة للشـرعية تكمـن في المجتمـع المـدني

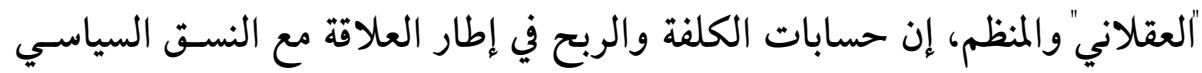

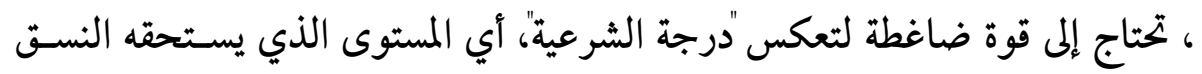

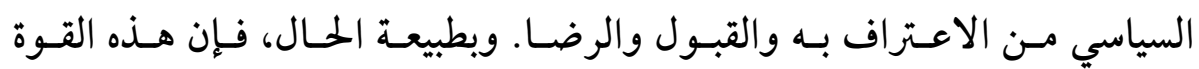

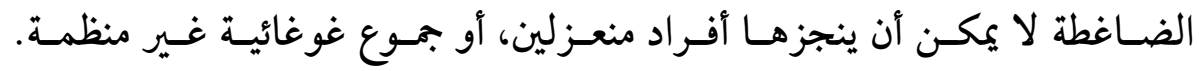

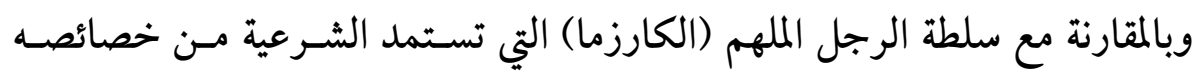

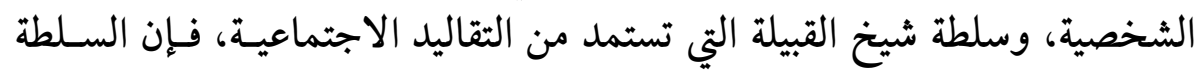

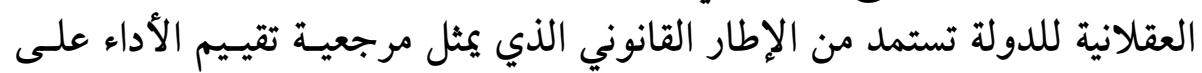

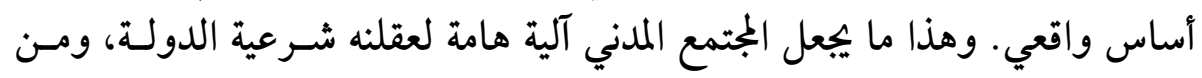
ثم جعلها خاضعة للنقاش والتداول بصورة مستمرة.

ومن هذا المنطلق، تظهر المسؤولية الأخلاقية للنظام السياسي إزاء المصـالح

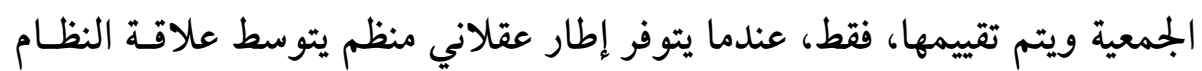

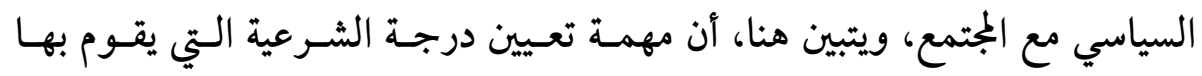

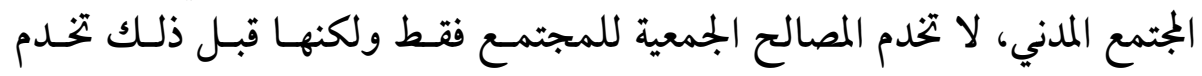

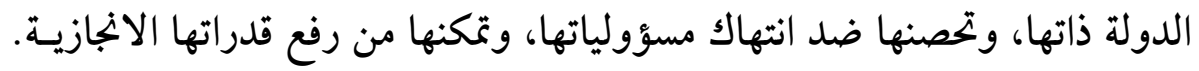


إن عقلنه شرعية الدولة على هذا النحو، تمكن النسق السياسي من إجراء عمليـات تصحيح وتقويم دائمة.

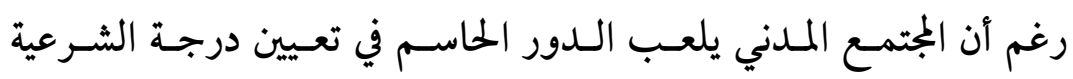

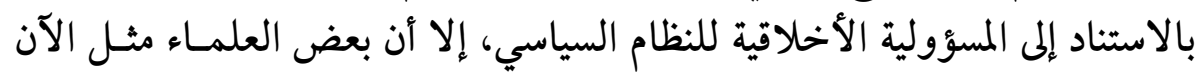

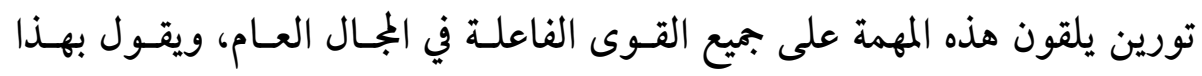

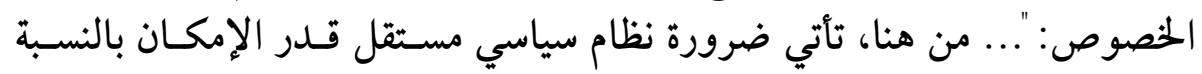

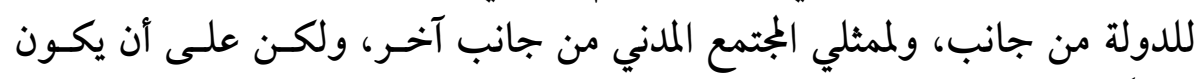

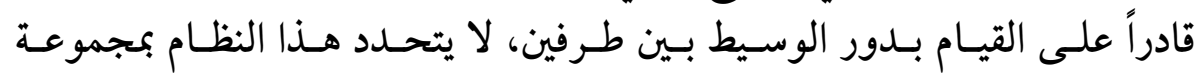

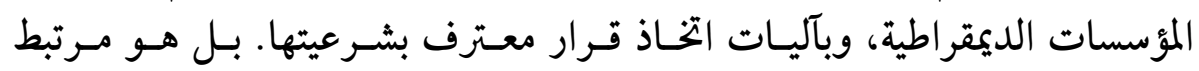

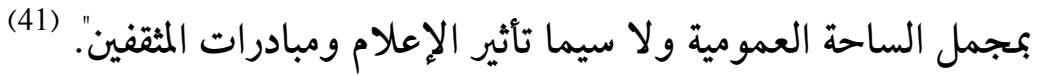

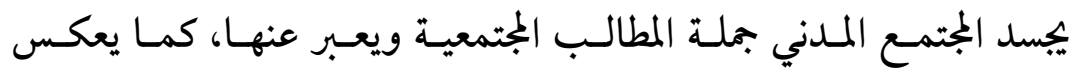

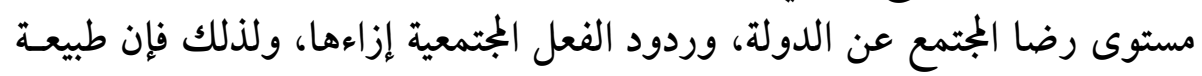

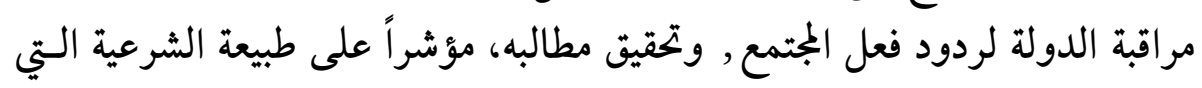

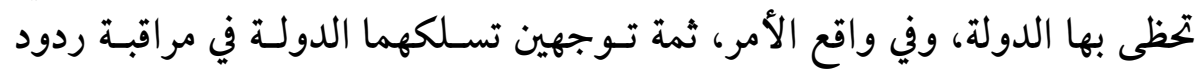

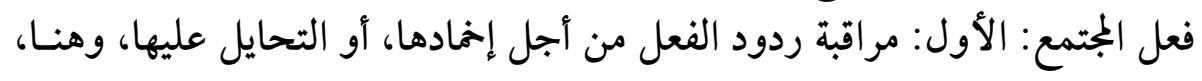

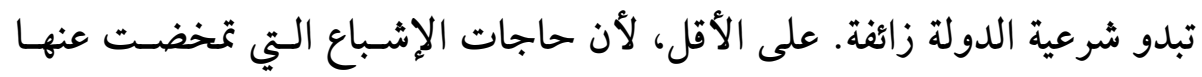

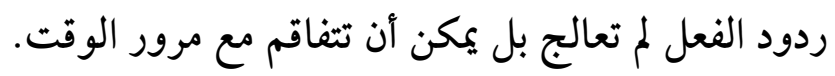

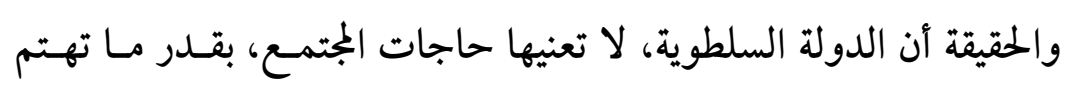

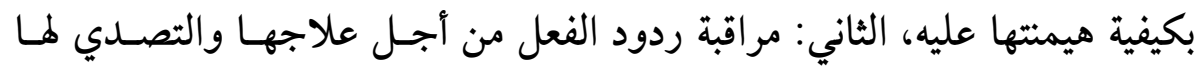

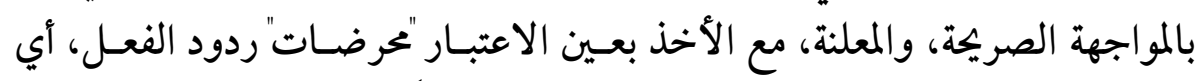

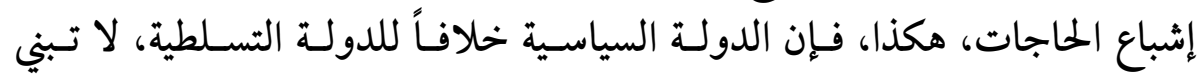

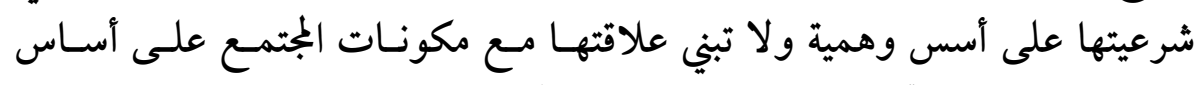

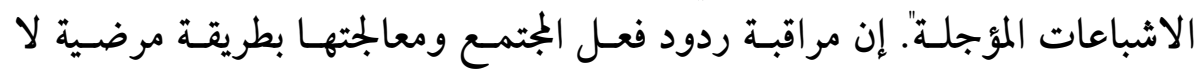

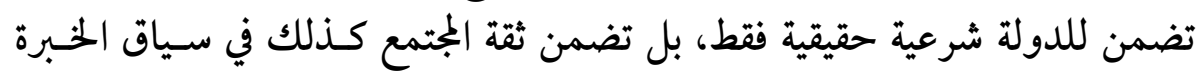

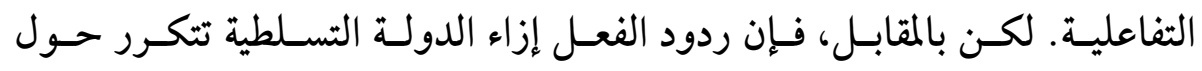




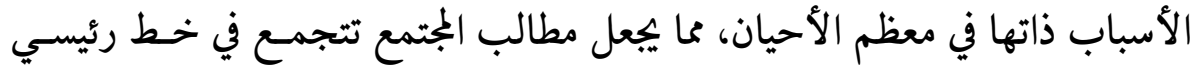

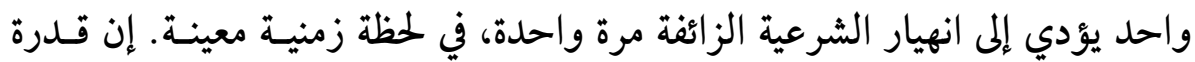

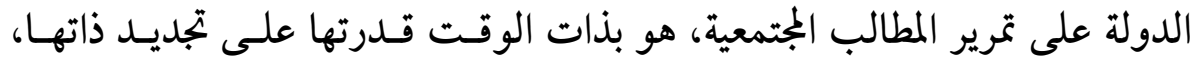
وتجديد المجتمع في آن معاً.

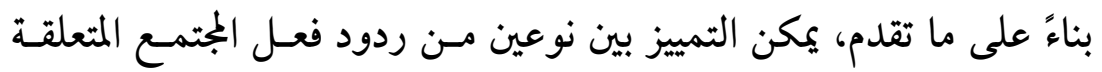

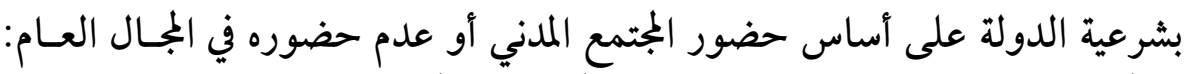

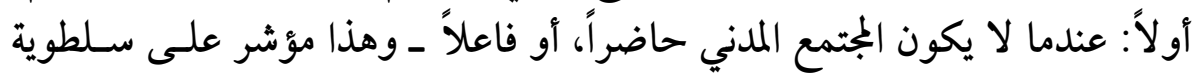

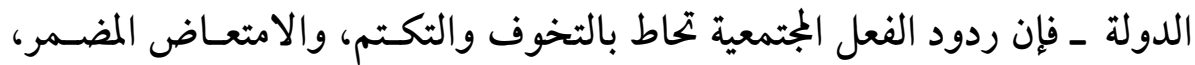

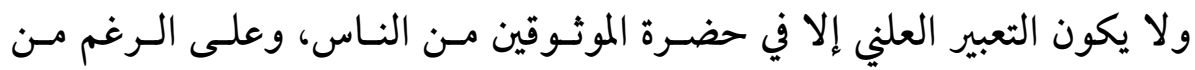

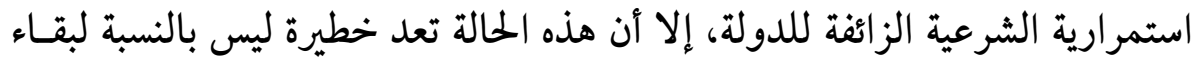

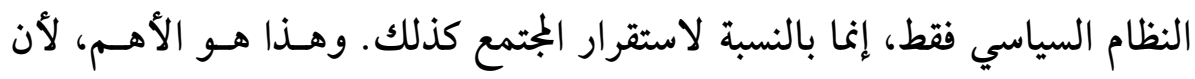

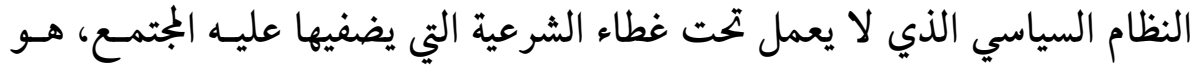

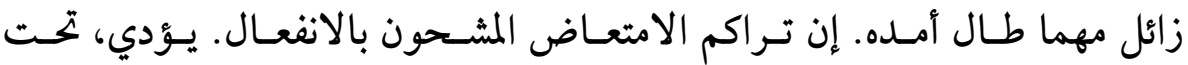

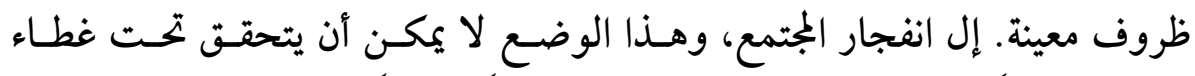

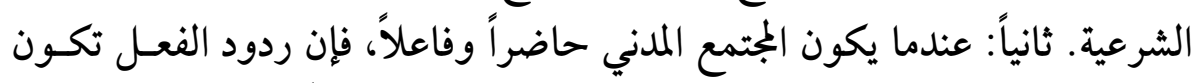

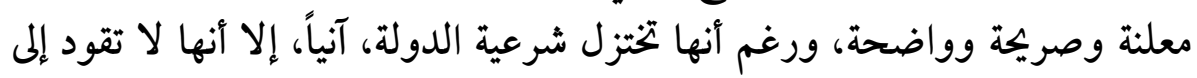

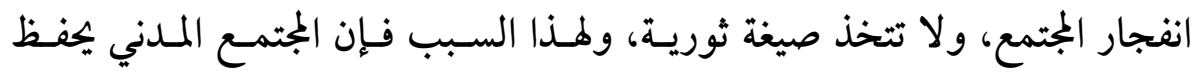

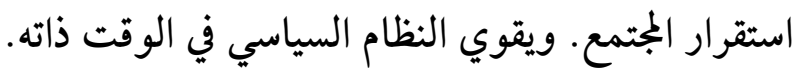

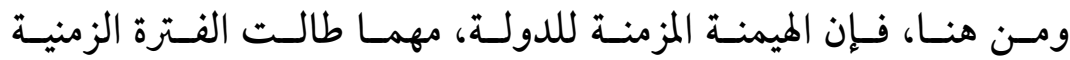

لاستقرارها، فإنها تدخل في أزمة شرعية معلنة. وكما يقول هابرماس Habermas

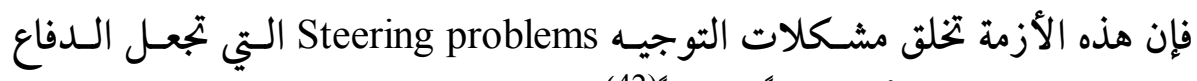

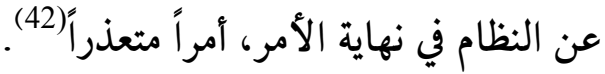

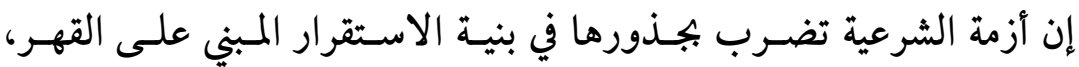

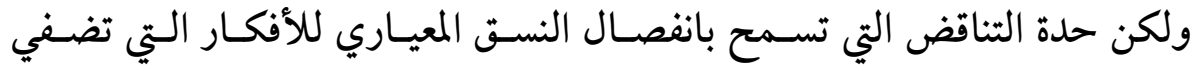

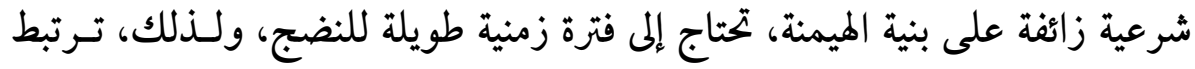


أزمة الشرعية أساساً بالثورة على الأوضاع القائمة كما ترتبط بالصراعات الكسبرى

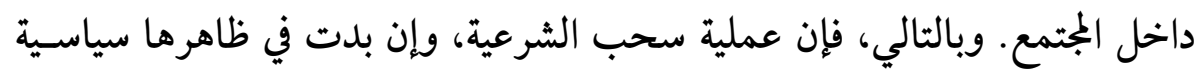
بالكامل، إلا أن أساسها الحقيقي، اقتصادي، وسياني، المياسي، واجتماعي، وثقافي.

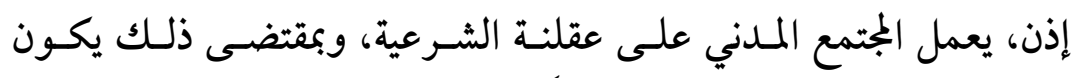

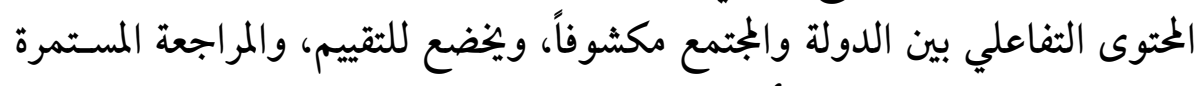

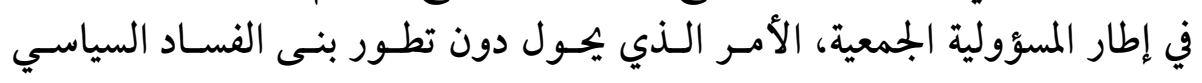

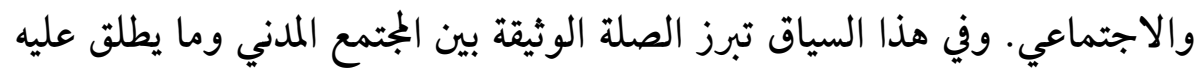

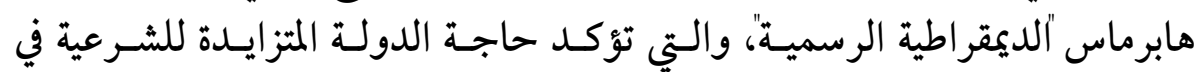

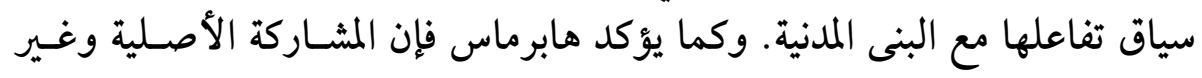

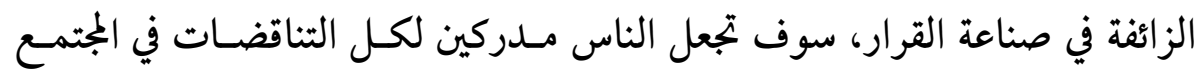

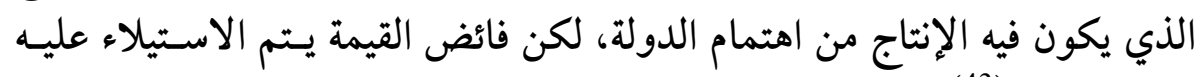
بصورة فردية (43).

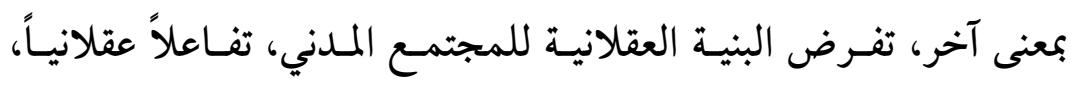

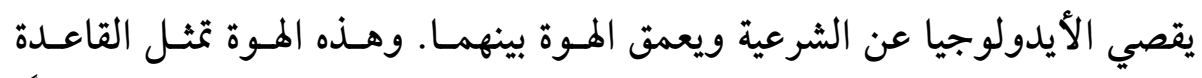

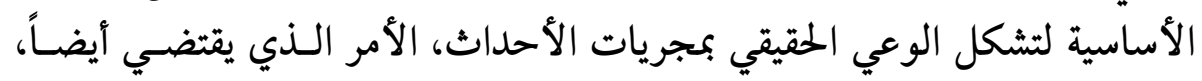

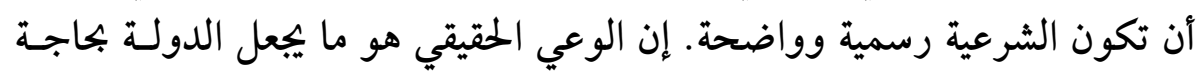

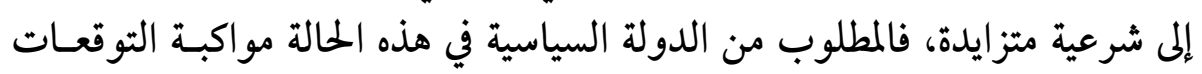

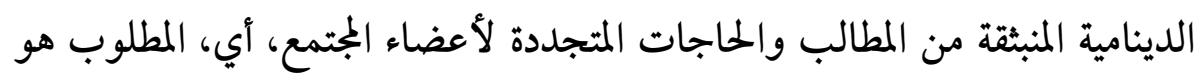

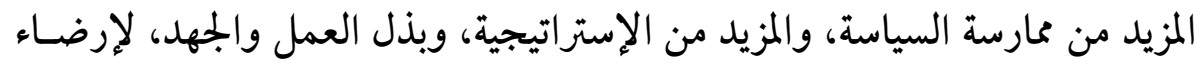

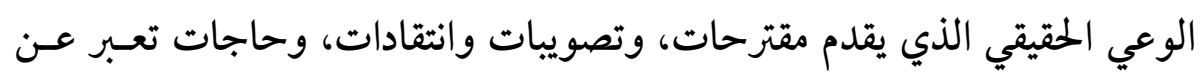

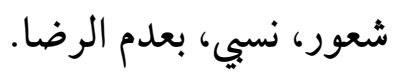

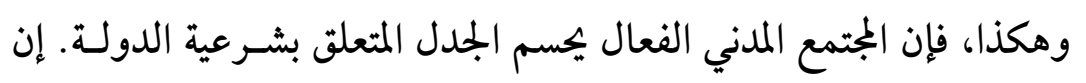

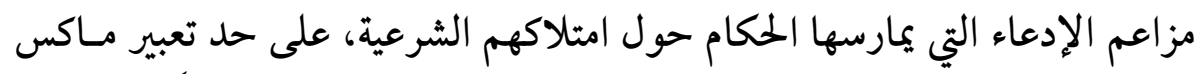

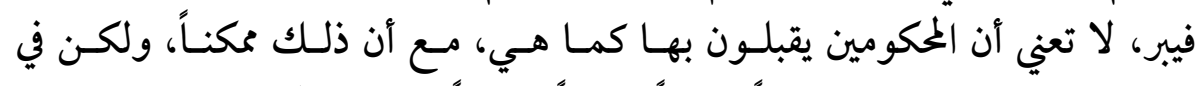

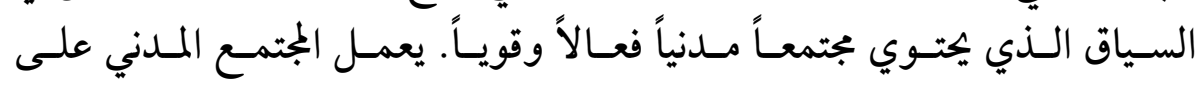




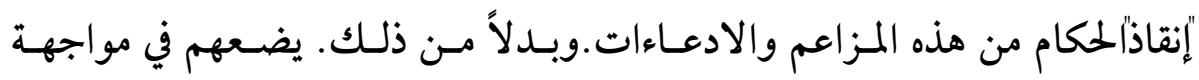
مباشرة مع البنى الواقعية للشرعية، قبل أن تنبثق أزمة الشرعية.

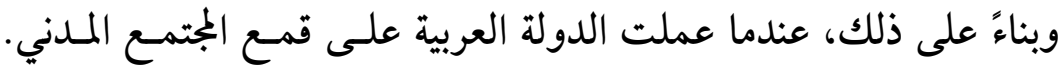

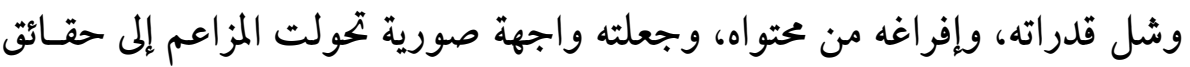

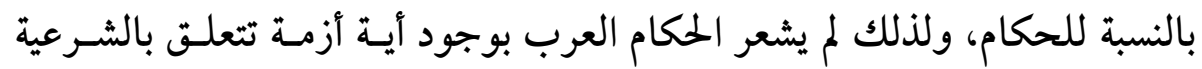

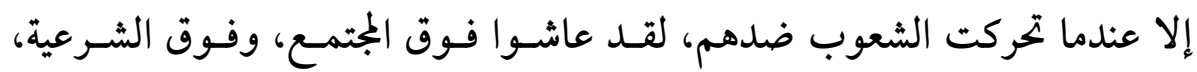

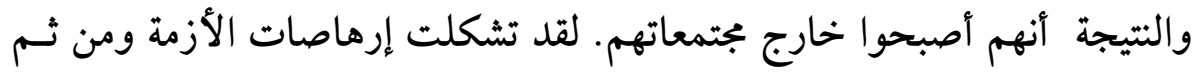

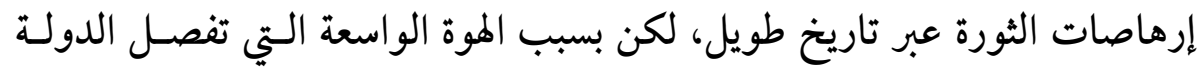

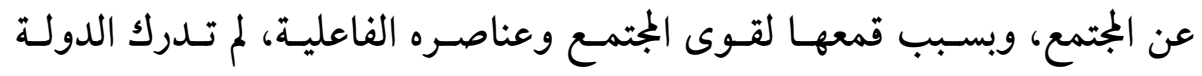

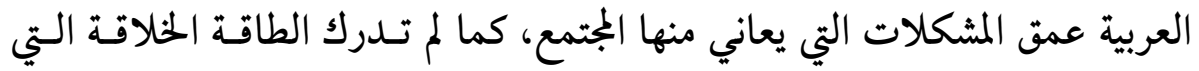

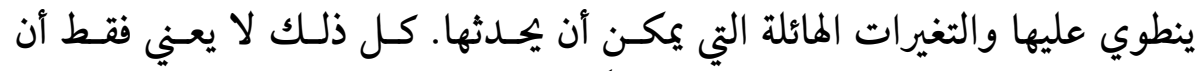

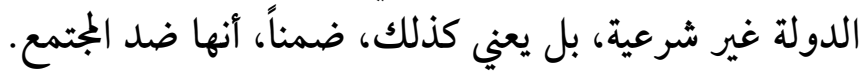

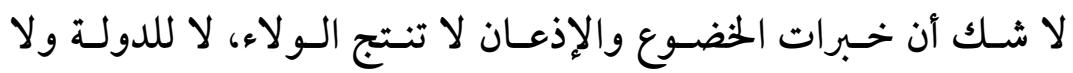

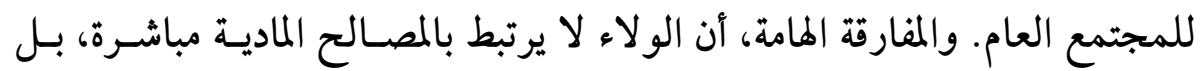

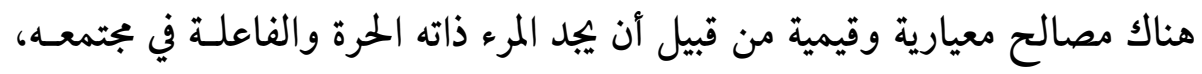

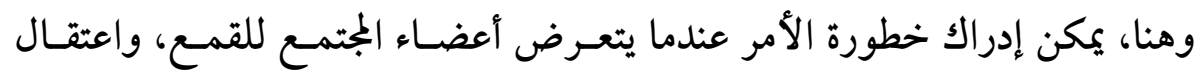

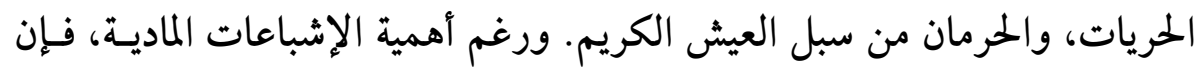

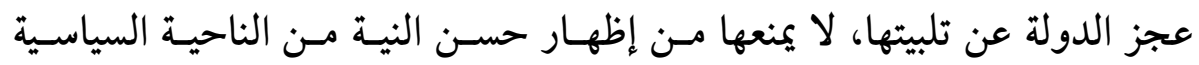

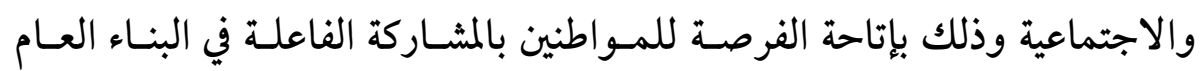
وتشييده، وللمجتمع المدني أن يتشكل وينمو بحرية.

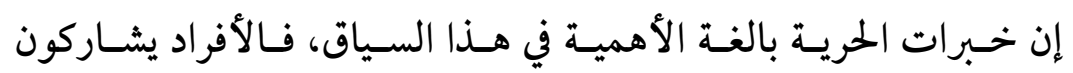

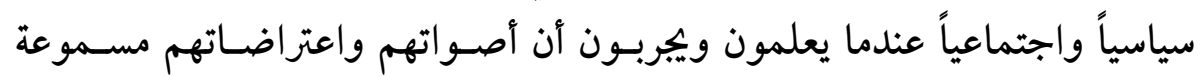

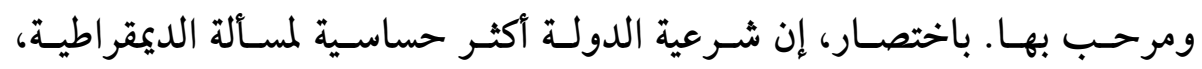

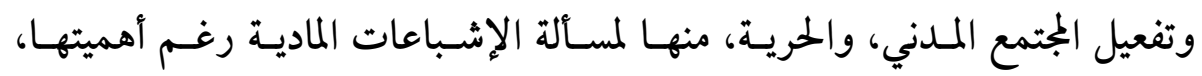

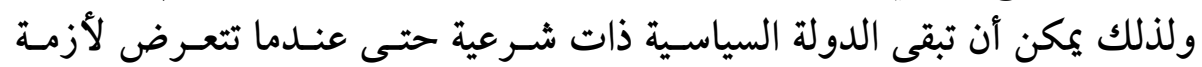




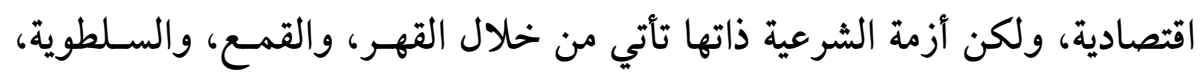

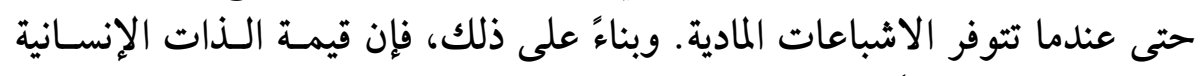
وكرامتها تتطابق تماماً مع فكرة الشرعية.

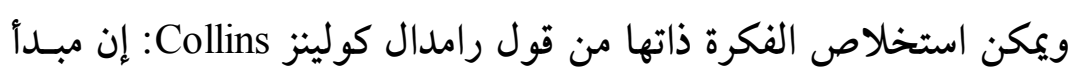

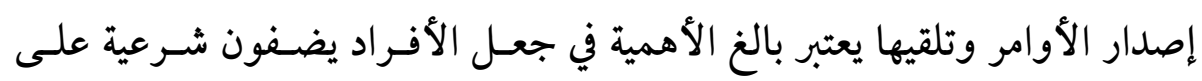

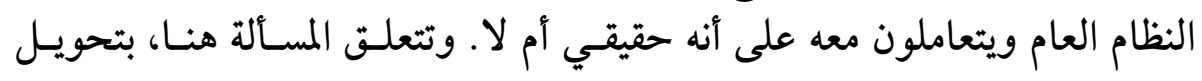

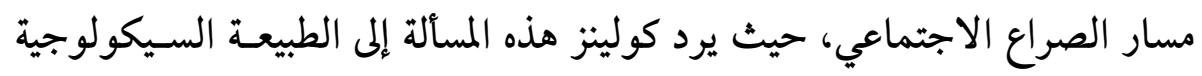

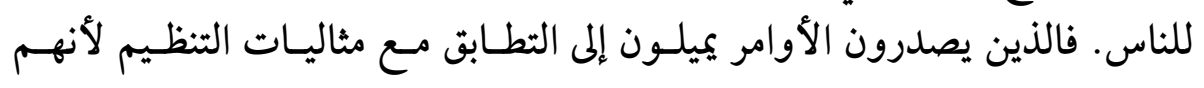

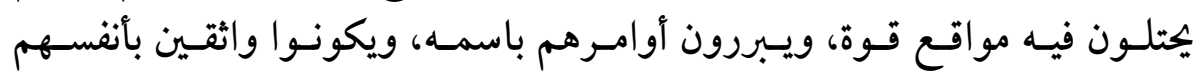

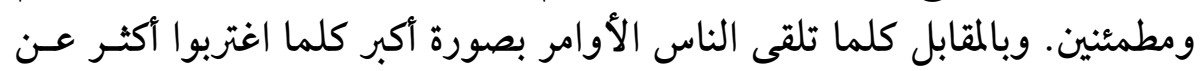

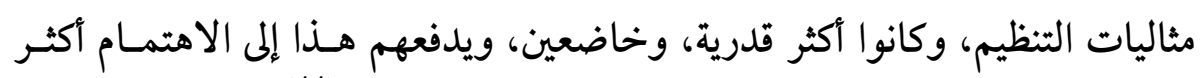
بالمكافئات الخارجية (المادية). ويكونوا غير ونير واثقين بالآخرين (44).

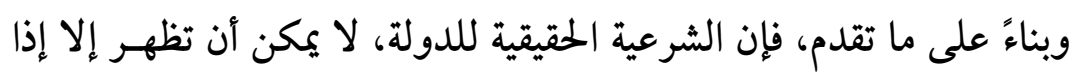

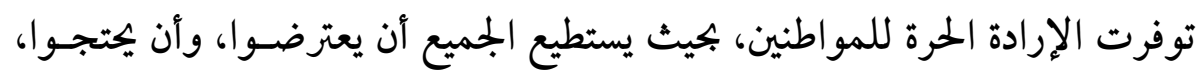

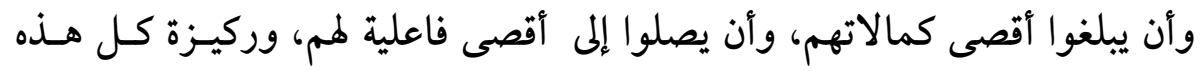

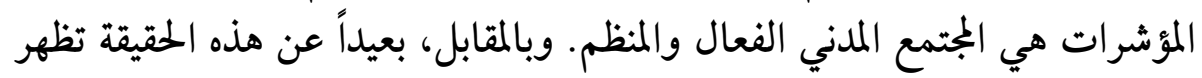

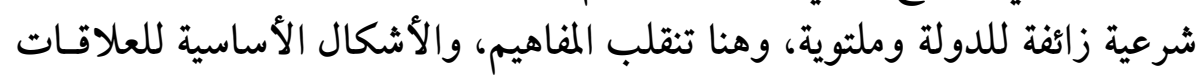

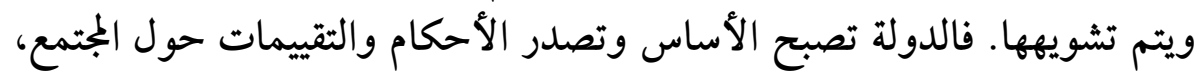

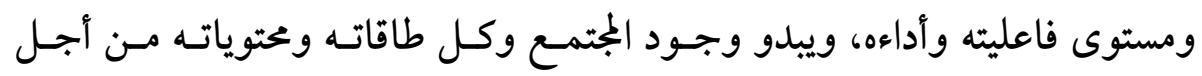

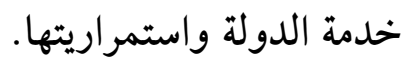

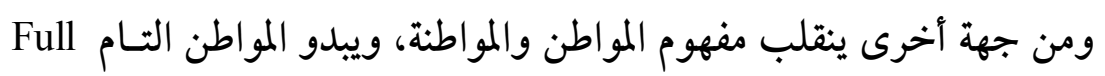

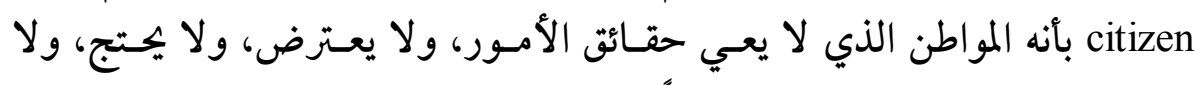

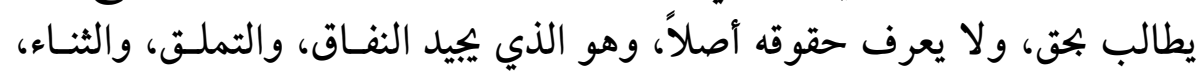

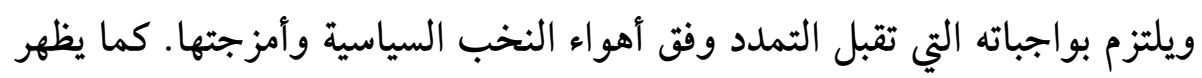

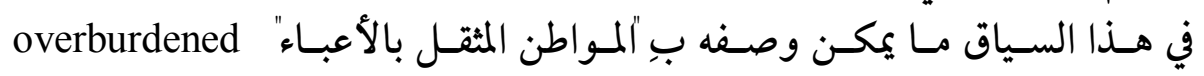


citizen وهو المواطن الذي يجمل ويتحمل كل إخفاقات الدولة وتعثرها وفشـلها،

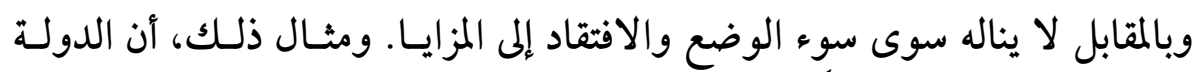

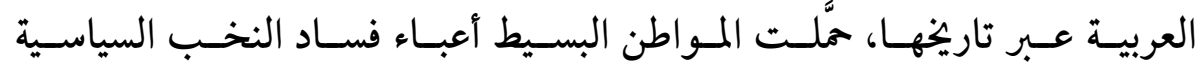

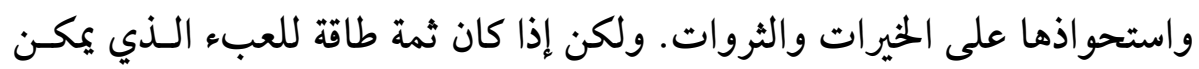

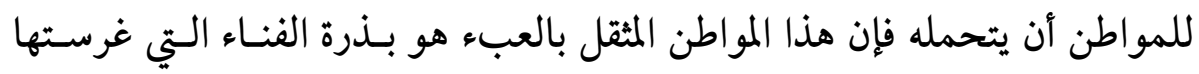
الدولة بسلطويتها.

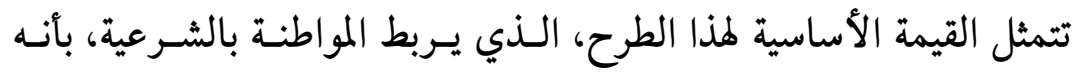

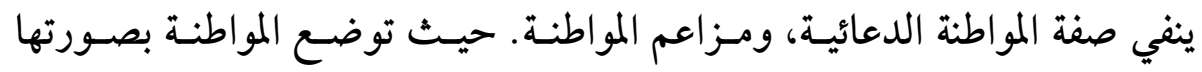

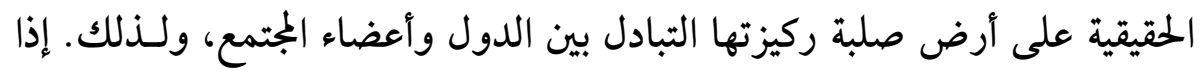

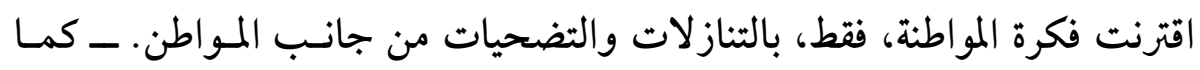

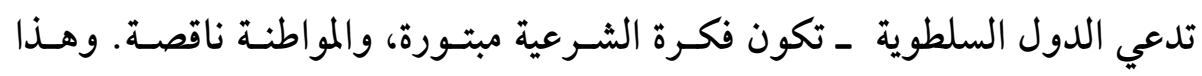

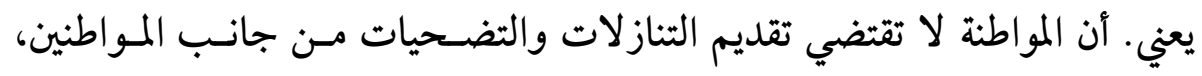

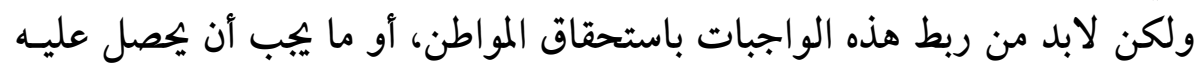

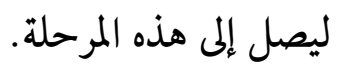

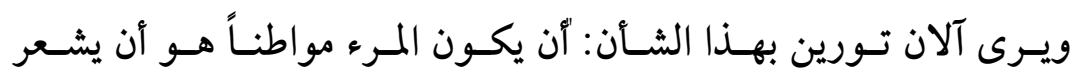

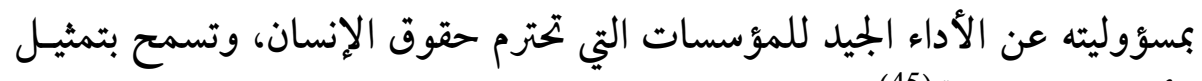

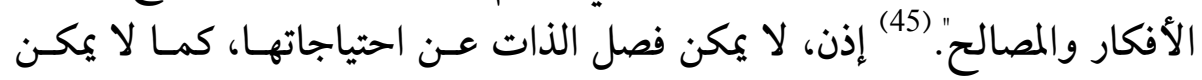

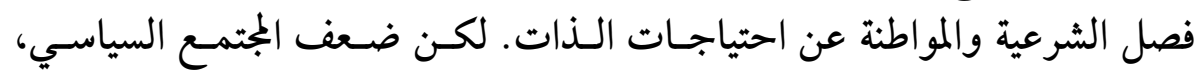

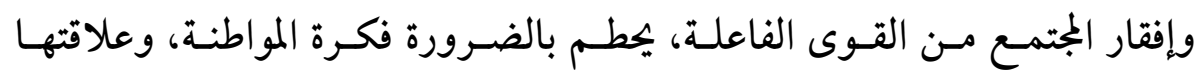

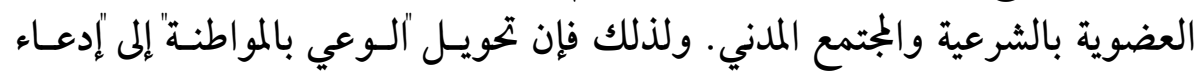

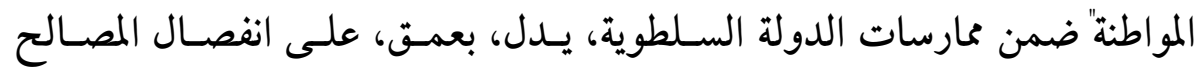

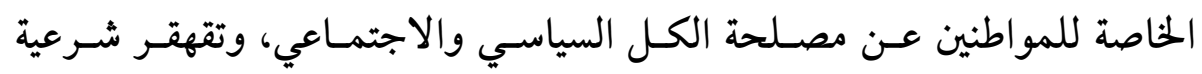
الدولة.

ويعود ذلك، إلى أن إدعاء المواطنة يعني غياب المرتكزات الحقيقية لشـرعية

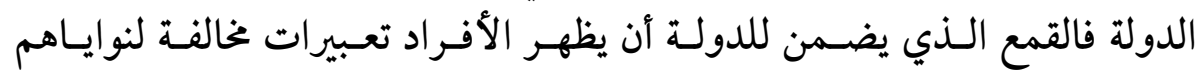


ومقاصدهم، لا يضمن هنـا بطبيعـة الحسال شـرعية حقيقيـة، طالمـا لا توجــد إرادة

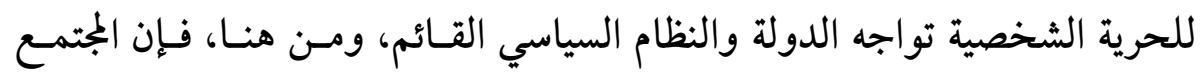

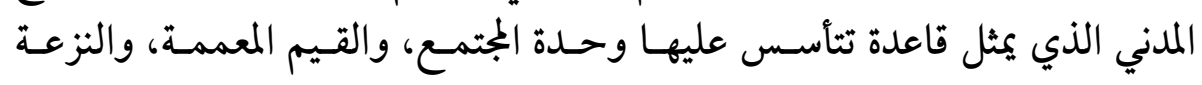

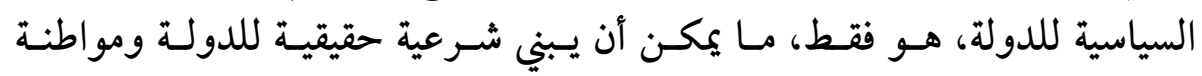

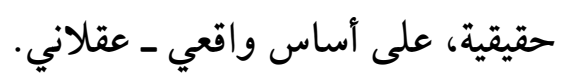

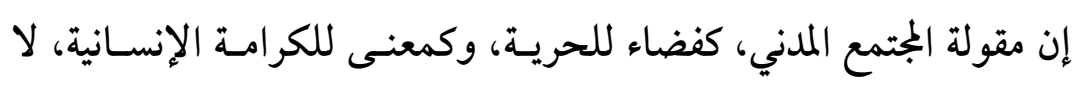

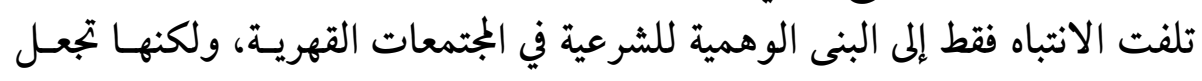

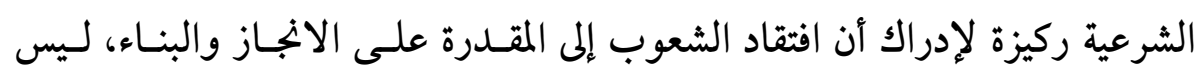

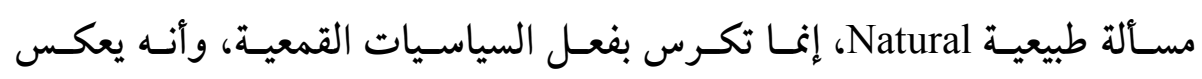

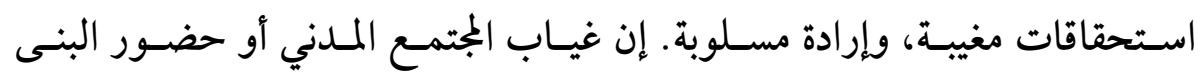

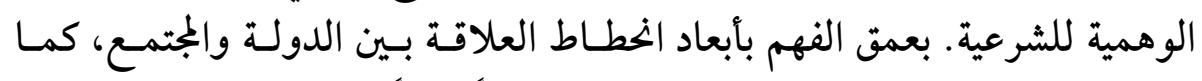

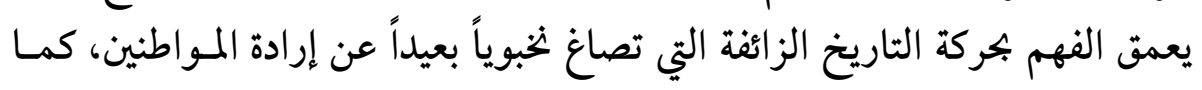

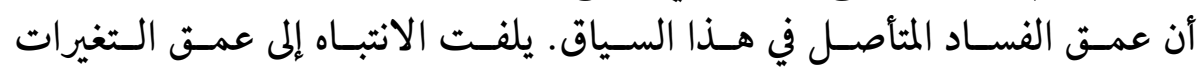

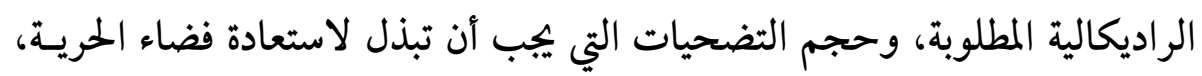
والقيمة الإنسانية. 


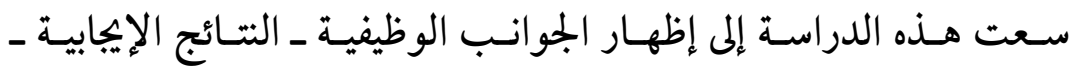

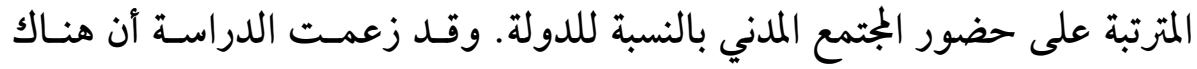

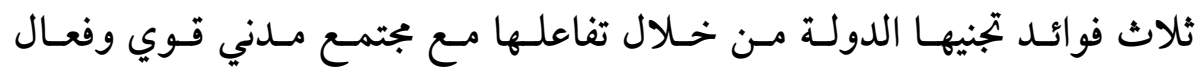

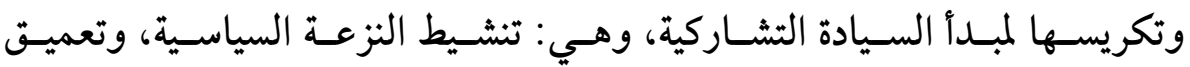

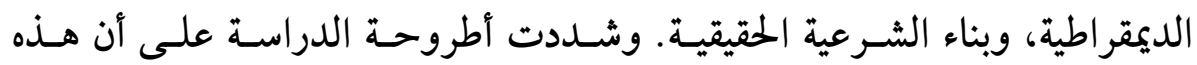

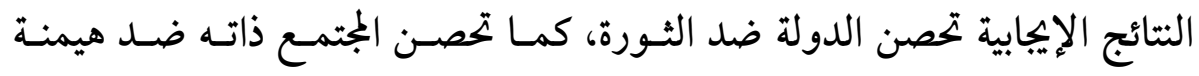

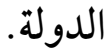

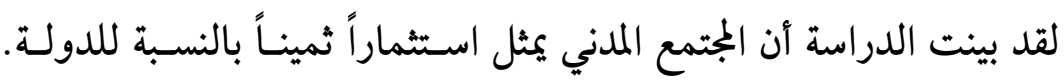

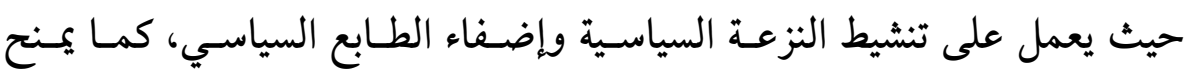

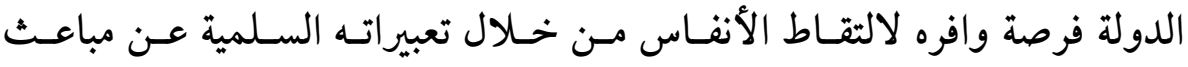

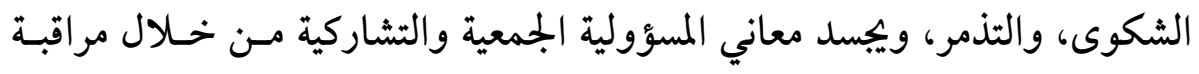
الأداء الحكومي وتحسينه وتوجيه الدولة ورفع مستوى الأداء وتقديم الخبرات

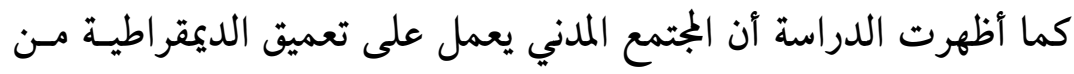

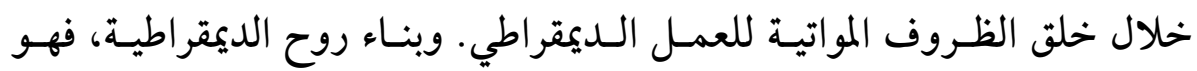

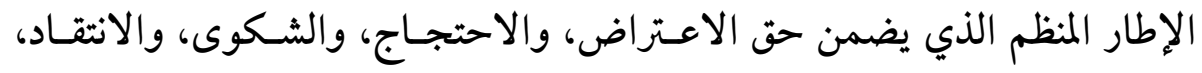

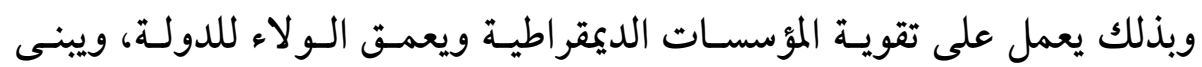

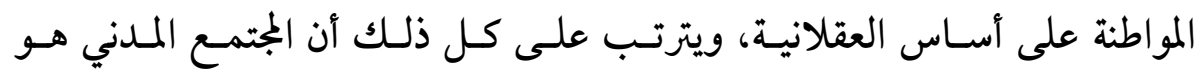

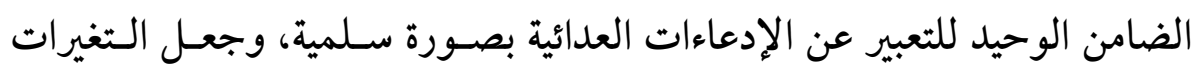
التي تحدث داخل المجتمع سلسة وتدريجية.

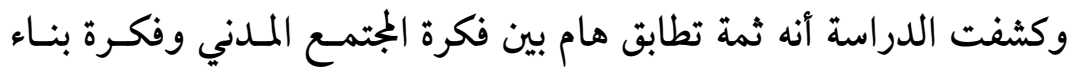

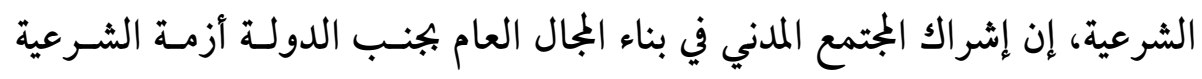

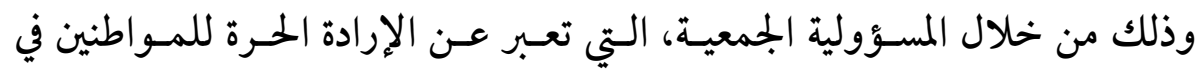


توجيه سياسة الدولة، كما يولد المجتمع المدني مسؤولية أخلاقية تضمن أداء الدولــة لوظائفها من ناحية، كما تضمن للدولة ركائز حقيقية لشرعيتها.

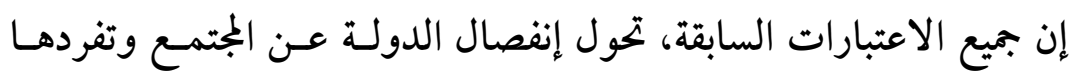

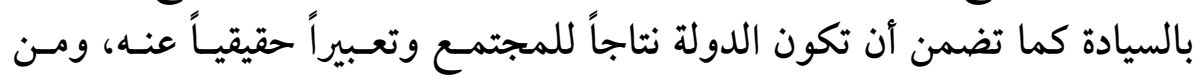

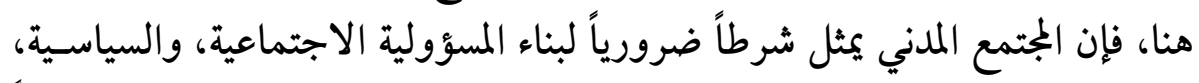

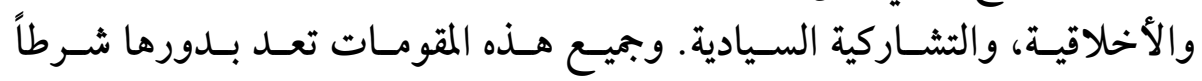
ضرورياً لاستمرارية الدولة وصيانتها. 


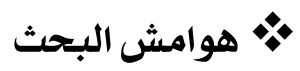

إبراهيم، سعد الدين، (1995)، سلسلة مشروع المجتمع المدني والتحـول الـديمقراطي في

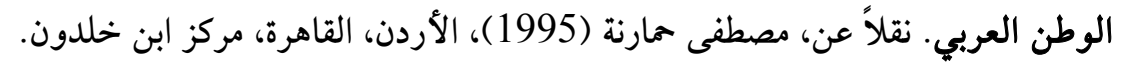

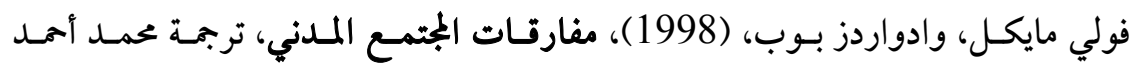

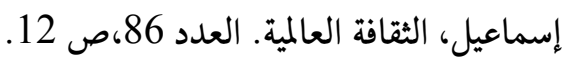

(3) Howards, Marc, (2003), The weakness of Civil Society in post Communist Europe,CambridgeUniversity press.

(4) Warren, mark, (2001), Democracy and Association, PrincetonPrinceton university press.

(5) Avritzer, Leonardo, (2002), Democracy and the Public Space In Latina America, Princeton, Princeton university press.

(6) Brysk, Alison (2000) Democratizing Civil society in Latina America, Journal of Democracy, Vol. 11, No 3, 151-165.

(7) Bacik, GoChan, (2008), Hybrid Sovereignty In The Arab Middle East, New York, Pal grave MacMillan.

(8) Von Rooy, Alison, (2004), The Global Legitimacy Game: Civil.

Society, Globalization, and protest, New York, Palgrave Macmillan.

(9) Hobbes, Thomas. (2006) Leviathan, New York, Dover publications. Skockpol,

(10) Theda, (1994), Revolution In The Modern world, Cambridge pine forge press.

(11) Skockpol, Theda, (1979), States and Revolution: A comparative Analysis of France, Russia, and china, N.Y, Cambridge university press. P x ii. 
(12) Udogu, E. Ike. (2007) African Renaissance In The Millennium: The political, Social, and Economic Discourse on The way forward, Lanham, MD, Lexington.

$$
\text { شويدلر، جيليلان، (1997)، المجتمع المدني ودراسة السياسة في الشرق الأوسط، ترجة }
$$

بركات، حليم (2000) المجتمع العربي في القرن العشرين، بحث في تغيير الأحوال

$$
\text { والعلاقات، ط } 1 \text { بيروت، مركز دراسات الوحدة العربية،ص } 923 .
$$

شويدلر، جيليان، (1997)، المجتمع المدني ودراسة السياسة في الشرق الأوسط، ترجمة

$$
\text { صادق عودة، عمان، دار سندباد،ص30. }
$$

(16) الحوراني، محمد (2008) النظرية المعاصرة في علم الاجتماع، التوازن التفاضلي صيغة

$$
\text { توليفية بين الوظيفية والصراع، عمان، دار مجدلاوي.186، }
$$

(17) Cohen, Cathy J. Kathleen B., Jones and Joan Toronto, (1997) women

Transforming politics: An Alternative Reader, New York, New York university press.

(18) كومار، كريشان، (2001)، حول مصطلح الجمتمع المدني: مذكرة إضافية عن مفهوم المجتمع المدني وميادينه، ترجمة عدنان جرجس، الثقافة العالمية، العدد 107.

(19) Akman, Ayham (2012) Beyond The Objectivist Conception of Civil Society, Social Actors, Civility and Self - limitation, political studies, Vol 60, 321-340.

(20) Houtzager, peter. (2001), collective Action and political Authority, Rural workers, Church, and State in Brazil Theory and Society, 30, $1-45$ 
(21) Bounce, V. (2003), Rethinking Recent Democratization. Lessons form the post communist Experience, world politics 55, 167-22.

(22) Ho, Ming - sho, (2012). Sponsoring Civil Society: State and Community Movement in Taiwan, Sociological Inquery. Vol 82. No. 3. 404-423.

${ }^{(23)}$ Bob, Edwards, Michael Foley and mariu Diani, (2001), Beyond

Tocqueville: Civil society and Social Capital. Debate, In, Comparative perspective, university of New England press.

(24) Putnam, Robert (1993) making Democracy work, Princeton, Princeton university press.

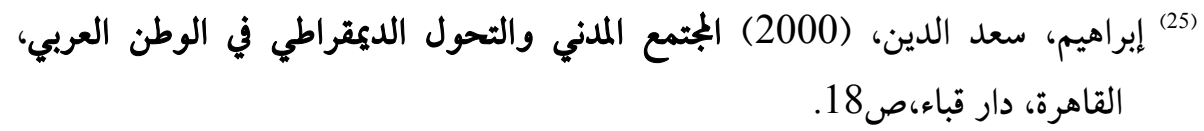

${ }^{(26)}$ Entails, J P. (1996) Civil Society and Authoritarian Temptation in Algerian politics, Islamic Democracy VS. The CentralizedState in, A. R. Norton (ed) civil society in the middle East, Vol (I I) Leiden E. J. Brill, 45-87.

(27) Linz, Juan Toes And Alfred stepan, (1996), problems of Democratic Transition and Consolidation, southern Europe, south America, and post Communist Europe, Baltimore; Johns Hopkins print.

${ }^{(28)}$ Roberts, Kenneth, (1998), Deepin Democracy? The modern Left and social Movements in chile and peru, Stanford university press.

$$
\text { (29) زاتيلن، ارفنج (1993) النظرية المعاصرة في علم الاجتماع، دراسة نقدية، ترجمة محمود عودة }
$$

${ }^{(30)}$ Norton, A.R. (1996), preface In A.R. Norton (ed), civil society in the middle East, Vol (I I), Leiden E. J. Brill PP. XV - x vil. 


$$
\text { (31) بركات، حليم، (1995)، الديمقراطية والعدالة الاجتماعية، ط1، رام الله، مؤسسة مواطن، }
$$

${ }^{(32)}$ Mann, Michael (1993) The Autonomous power of the state, In Marvin Olsen, and Martin Marger, Power In Modern Societies, west View ress.Inc.

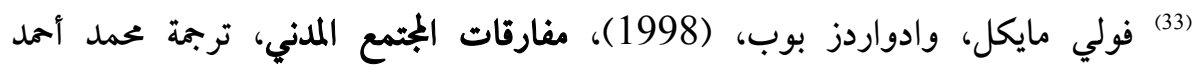

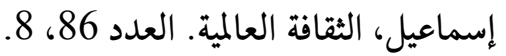

$$
\begin{aligned}
& \text { (34) شويدلر، جيليلان، (1997)، المجتمع المدني ودراسة السياسة في الشرق الأوسط، ترجمة } \\
& \text { صادق عودة، عمان، دار سندباد،30. }
\end{aligned}
$$

${ }^{(35)}$ Sickle, Alix Van (2011) Beyond Electoral Democracy: Civil Society and The construction of Democratic citizenship In Latin America, pro Quest. L L C.

${ }^{(36)}$ Cohen, Jean L. (1982) Class and civil Society, The limits of Marxian Critical Theory, Amherst, The university of Massachusetts,35

(37) Dalton, R. J (2004) Democratic Challenges, Democratic Choices: The Erosion of Political Support in Advanced Industrial Democracies, Oxford, Oxford university press.

(38) Chandhoke, Neera (2003) A Critique of Civil Society As A Third sphere. In, Rajesh Tandon and Ranjitamohanty (eds) India, New Delhi, sage, 198-242.

$$
\text { (39) ملال، جميل، (1996)، الدولة والديقراطية، ط1، رام الله، مؤسسة مواطن، }
$$

(40) Adriaansens, Hans P. M. (1980) Talcott Parsons and The Conceptual Dilema, London. Routledge and Keganpaul.

(41) تورين، آلآن، (1997): نقد الحداثة، ترجمة أنور مغيث، القاهرة، المجلس الأعلى

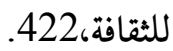


(42) Habermas, Jurgen, (1975) Legitimating crisis, Translated by Thomas McCarthy, Boston, Beacon press.

${ }^{(43)}$ Habermas, Jurgen, (1975) Legitimating crisis, Translated by Thomas McCarthy, Boston, Beacon press.

(44) Collins, Randal (1975) conflict sociology, Toward An Explanatory Science, New York, Academic press.

(45) تورين، آلآن، (1997): نقد الحداثة، ترجمة أنور مغيث، القاهرة، المجلس الأعلى للثقافة،242. 